\title{
الرحالات الجغرافية الى بلادً الهند والصين \\ في القرن الرابع الهجري/ العاشر الميلادي
}

أ.م.د. عكرمة كامل محمد الساعدي

الجامعة المستنصرية/ كلية التربية

قسم التاريخ الاسلامي

dr.ikrima2020@gmail.com
الباحث احمد نشمي جياد العلياوي

الجامعة المستتصرية/ كلية التربية

قسم التاريخ الاسلامي

nashmi20202@gmail.com

(مُلَخَّصنُ البَحثث)

تعد كتب الرحلات الجغرافية من اهم المصنفات في التاريخ الاسلامي بل هي عماد نلك المصنفات، وذلك لمـا احتوته من مـادة علميـة غزيرة في وصف البلدان ومدنها وعاداتها وتقاليدها وقد اعتمدت عليها اغلب المصـادر الاوليـة والمراجع الثانويـة في ذكر ووصف فيف

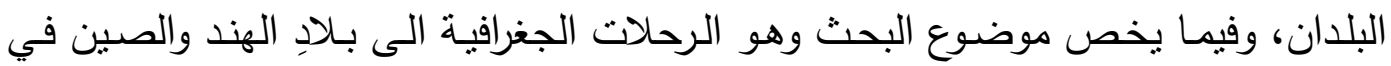
القرن الرابع الهجري فقد برز عدد من الرحالة في ذلك القرن منهم من ارتحل الى بلادِ الهند

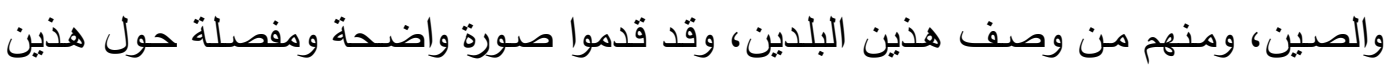
البلدين، لذلك تتاولتهم الدراسة بصورة تفصيلية من حيث تراجمهم ومنهجهم ورحلاتهم الى بلادِ الهند والصين وللموضوع اهية كبيرة لاته يسلط الضوء على اهم الرحالة الى بلادِ الهند والصين في ذلك القرن.

الكلمات المفتاحية: (الرحلات الجغرافية، الرحلة، الرحالة والجغرافيين) (المقدمة بسم الله الرحمن الرحيم

الحمد لله رب العالمين والصلاة والسلام على سيدنا ونبينا محمد خير الانام وعلى اله له وصحبه الغر الميامين ومن اتبعهم بإحسان الى يوم الدين. ان كتب الرحلات قدمت وتقدم في مجال التاريخ بعض المعلومات التي لم يقدمها لنا علم مختص في هذا المجال، فاذا كانت كتب التاريخ العام وبحسب تصانيفها قد تطرقت الى جانب واحد في تاريخ واحداث البلدان، فأن هذه جمعت وتطرقت الته الى كافة الجوانب منها الاجتماعية والسياسية والاقتصادية والعمرانية والثقافية، كذلك تطرقت بعضها عن الطبقات والتراجم، كما تضمنت كتب الرحلات بعض الاحداث السياسية واسماء السلاطين والامراء والعلماء ورجال الدين التي لم نجدها في كتب التاريخ العام، ولولاها لم تظهر هذه الاسماء

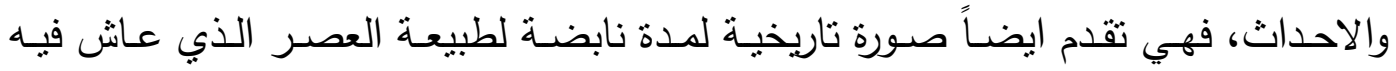


الرحالة، ونحن نجد فيها قصص تحكي بعضها احداثاً مستمدة من الواقع في الرحلات تُعرفنا

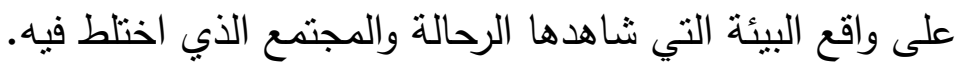

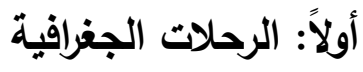

عند بدايـة القرن الثناني الهجري/ الثامن الميلادي، كان العرب قد امتدت فتوحاتهم

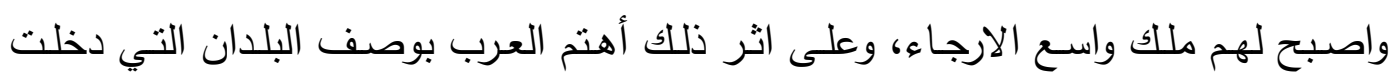

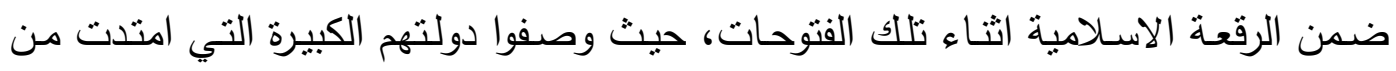
بلاد الهند وحدود الصين الى الاندلس، ومن القوقاز واسيا الصغرى الى السودان ومجاهل

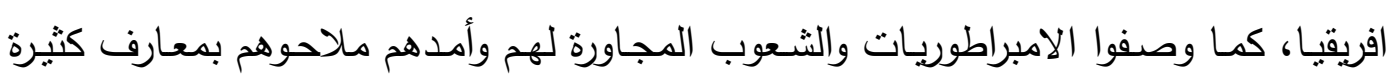

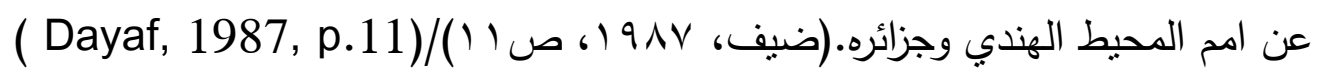

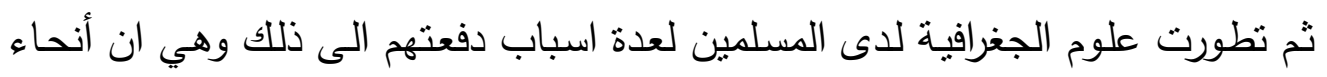

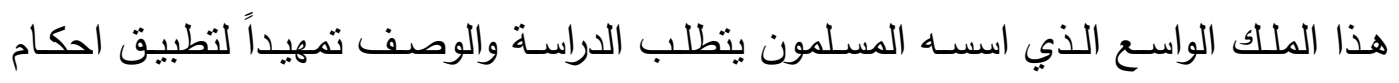

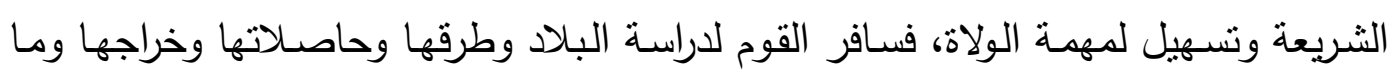

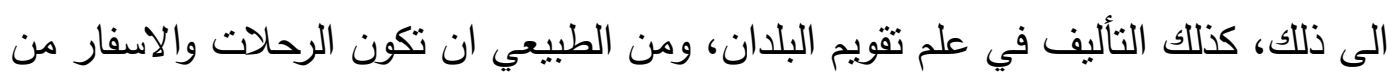

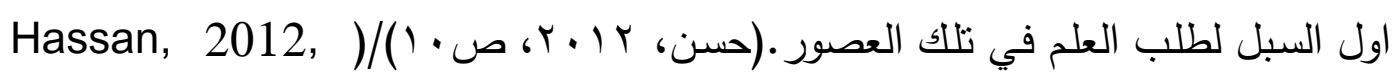

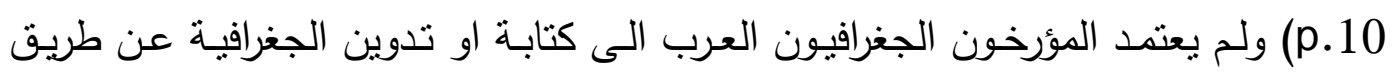

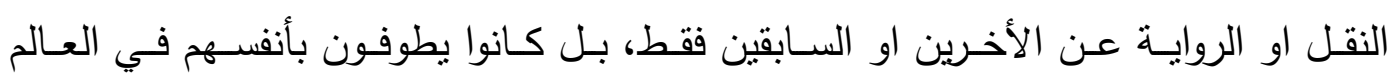

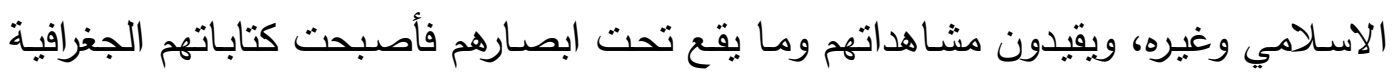
في كثير من صورها رحلات بالمعنى الدقيق، تصور احوال الناس والعمران بالعين الباصرة

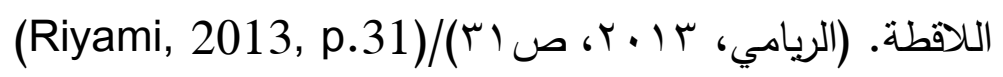

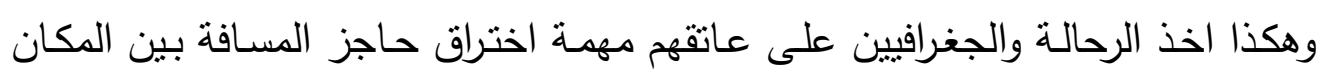

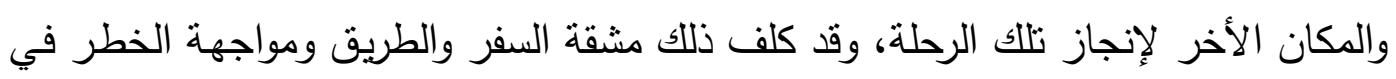
البر والبحر ومتاعب الاغتراب لبعض الوقت او لكل الوقت وصولاً الى الغايـة المباشـرة

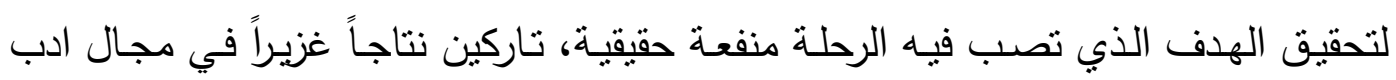

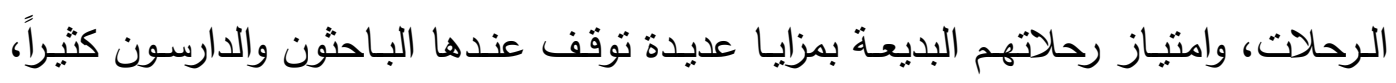

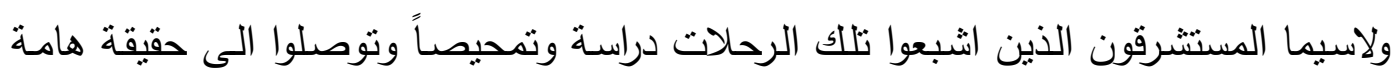

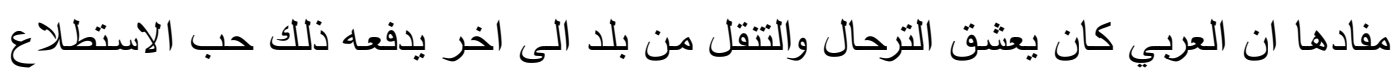

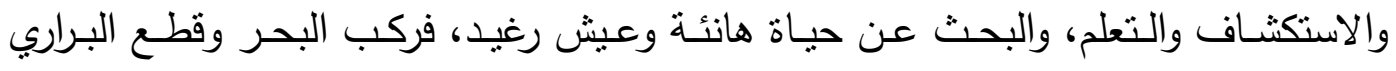
والصحاري بشجاعة لملاقاة عوالم اخرى وشعوب مختلفة ليعود الى مسقط رأسه منتشياً وفرحاً

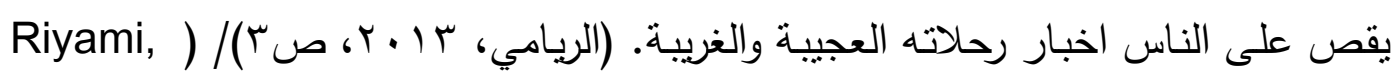
(2013, p.3 


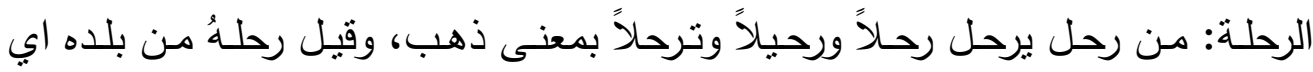

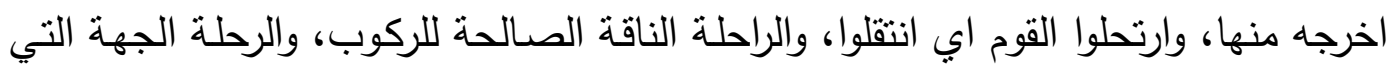

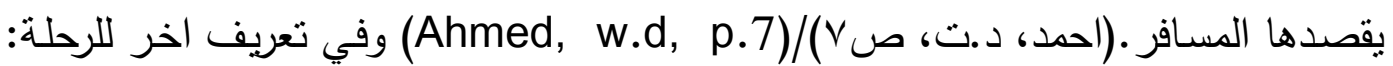
هي الوجه الذي تأخذ فيه وتريده، والرحيل: اسم ارتحال القوم للمسير ، ومفهوم الرحلة ماهية لهالية

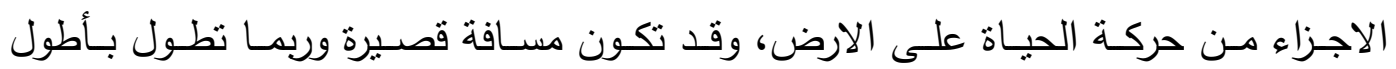

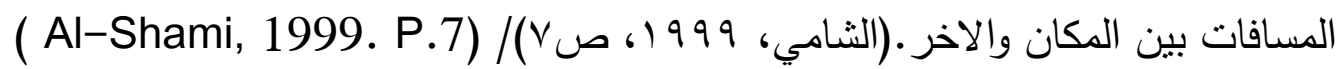
وكل هذه المفاهيم للرحلة كانت الجوانب المادية للحضارة الاسلامية اخذت منذ البداية تخطوا بخطوات بطيئة متزنة، ثم اخذت بخطوات واسعة بالرحلة والترحال، رغبة في ارتياد

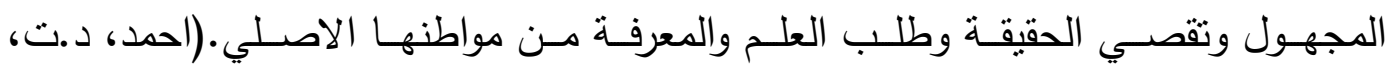

(Ahmed, w.d, p.7)/(V)

ومن وراء كل رحلة دافع او دوافع كي تحقق الهدف والغاية، وقد تكون الرحلة هواية

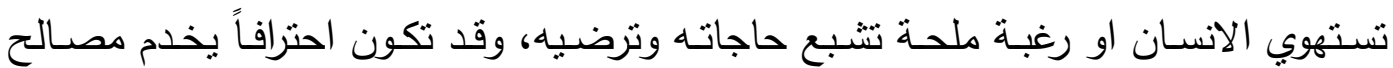

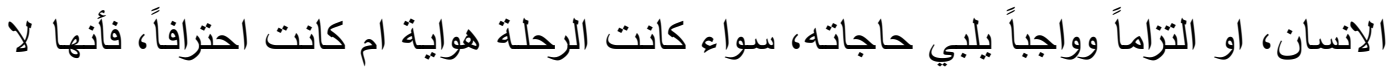
تتجرد من الهدف وهي تقصي ما في الارض ولا تكاد تتجرد من المسؤولية واستشعارها ولا

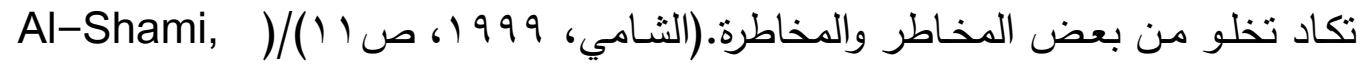
(1999. P.11

اما تعريف الجغرافية: وهي كلمة يونانية تعني صورة الارض، ويقال جغراويا بالواو على

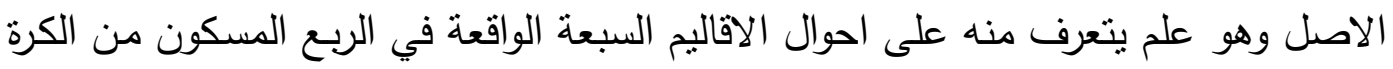

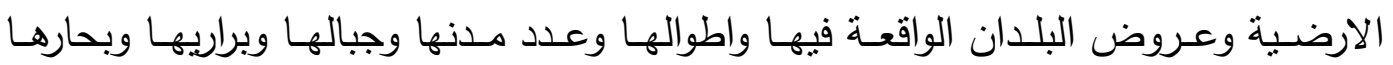

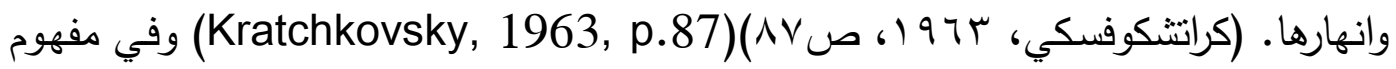

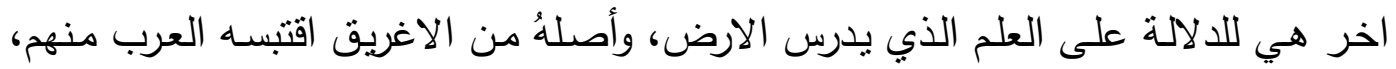

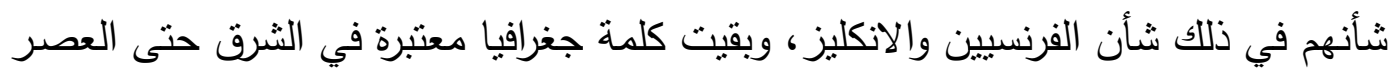

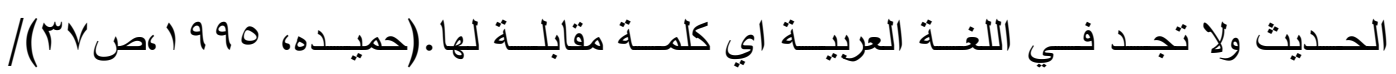
(Hamidah, 1995, p.37)

وقد استخدم العرب اربعة اصطلاحات للالالة على علم الجغرافية، وهي علم الاطوال والعروض، وعلم تقويم البلدان وعلم المساللك والممالك، وعلم عجائب البلدان، والاصطلاحان

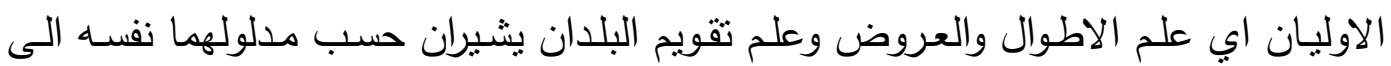
دراسـة جغرافية الكون(كوزموغرافيا) وعلم المصورات(كارتوغرافيا) والى تحديد عرض وطول المدن ولتقسيم الارض الى مناخـات، والى صنع قوائم تضم التضـاريس الجغرافيـة والبلدان 
والمدن التي تثير باختصار الى الجغرافية الرياضية، اما المصطلحان الاخران(علم المسالك

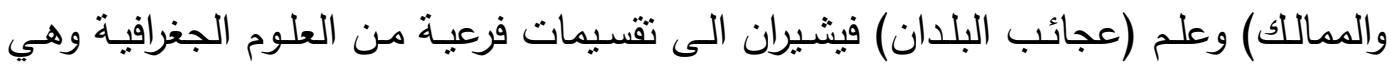
اللقاء نظرة اجمالية على الارض والعالم بمعزل عن الصبغة التقنية وعن جفاف الجغرافية

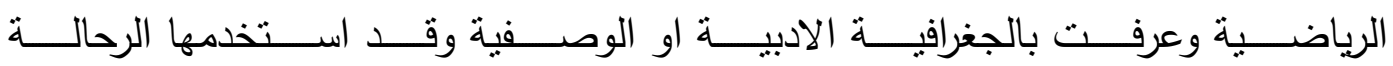

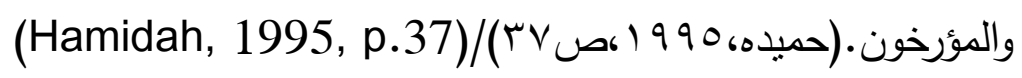
ثالثاً: رحالة وجغرافيو القرن الرابع الهجري/العاشر الميلادي اللى بلادٍ الهند والصين

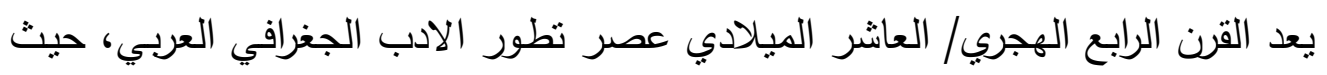

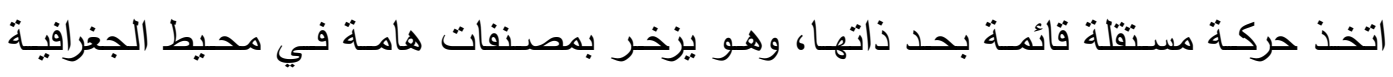
الاقليمية، ولم يقف الادب الجغرافي العربي الى هذا الحد فقد اخذ في هذا القرن ايضاً تشكيل

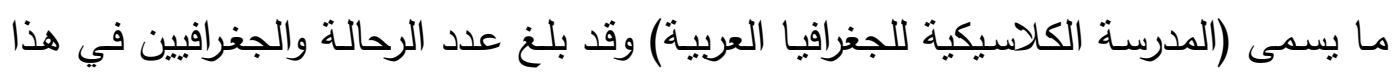
القرن عدداً كبيراً، وجاب البعض منهم الاصقاع الثمالية والبعض الاصقاع الجنوبية كالهند

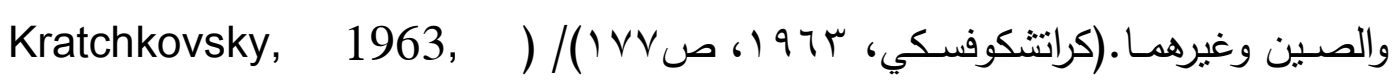

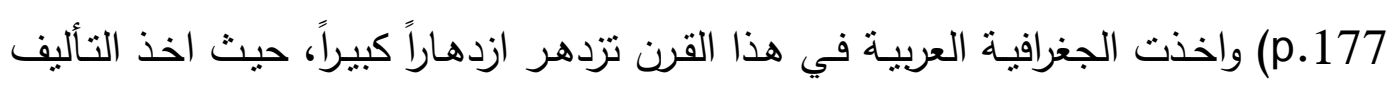

$$
\text { الجغرافي بعدة اتجاهات منها: }
$$

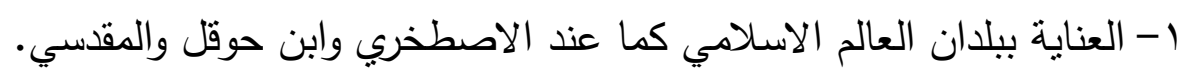

$$
\text { r - التخصص في بلد واحد. }
$$

r- في ذللك العصـر نشـأت المعجمات الجغرافيـة والتي بلغت ذروتهـا في القرن الخـامس

$$
\text { الهجري/ الحادي عشر ميلادي كمجم ياقوت الحموي (البلدان). }
$$

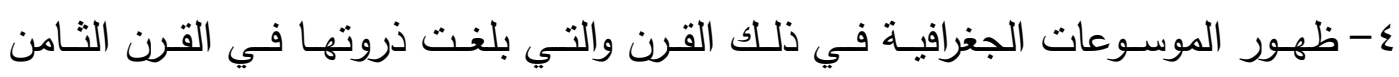

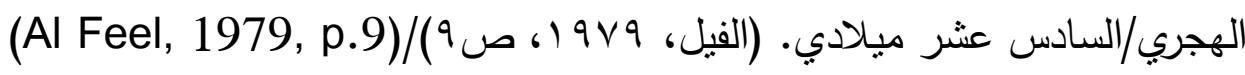

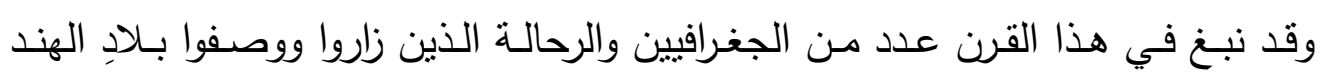

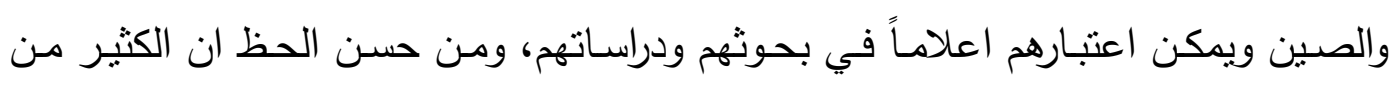

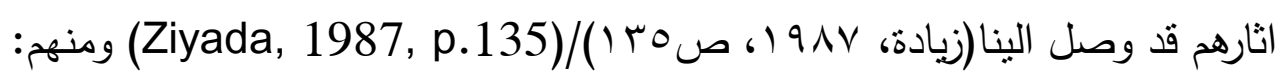
1-السيرافي/ رحلة السيرافي الى الهند والصين:

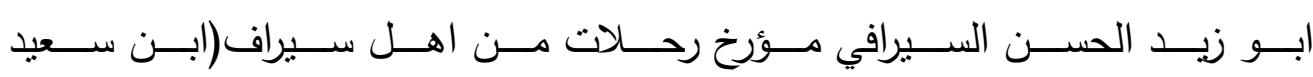

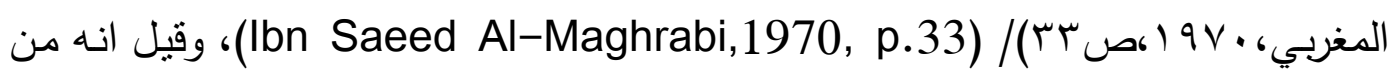

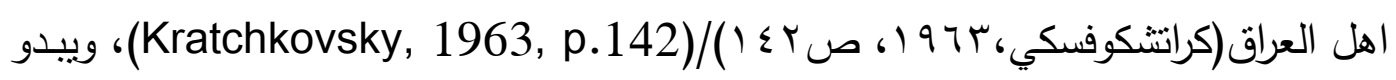

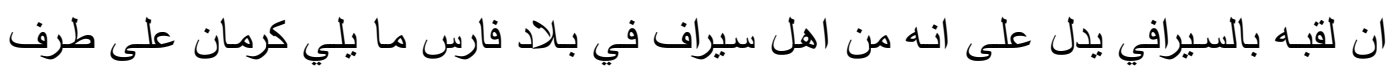

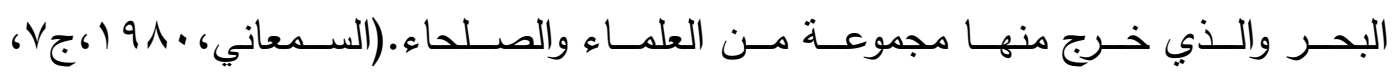

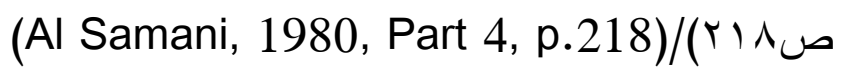


عاش السيرافي في القرن الرابع الهري/ العاشر الميلادي واخذ يدون قصص الرحالة والجغرافيين ومنها رحلة سليمان التاجر، ويعتبر صاحب الفضل في تدوين هذه الرحلة، وقد ذيل عليها شيء من القصص وبعض اخبار الهند والصين التي جمعها من اقوال الرحالة

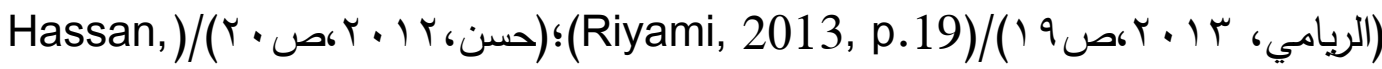

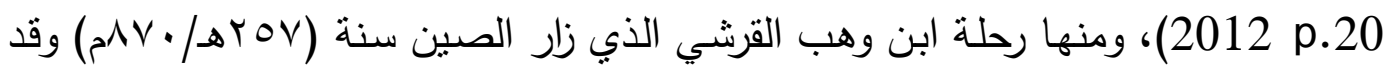

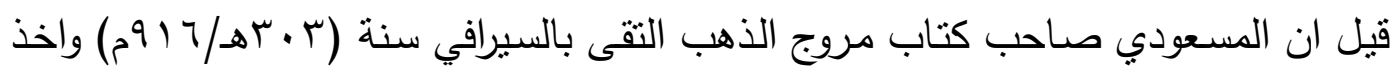

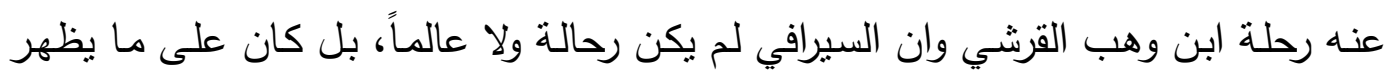

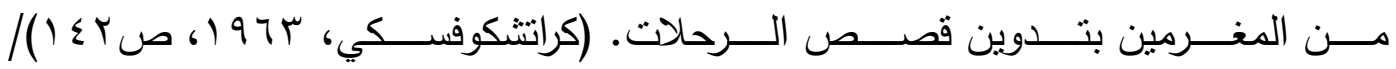
(Kratchkovsky, 1963, p.142) وفاته، وذكرت بعضها انه من مؤرخي اوائل القرن الرابع الهجري/ العانشر الميلادي. (زيادة،

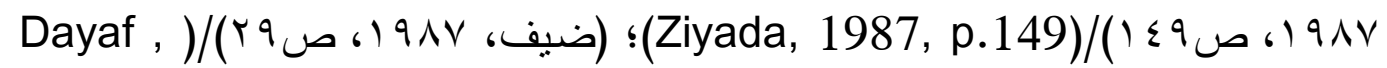
(1987, p.29

\section{وصف الكتاب ومنهجةُ}

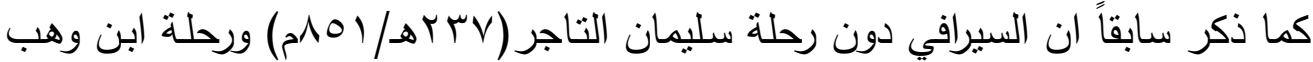

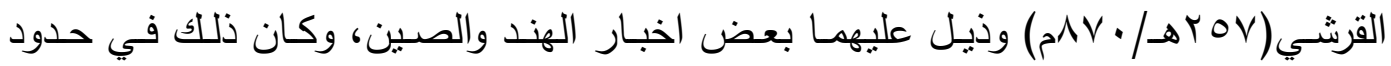

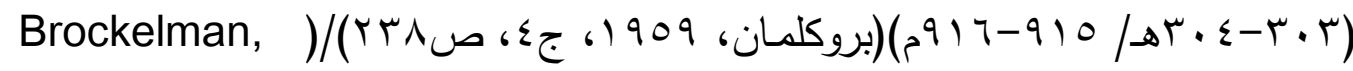

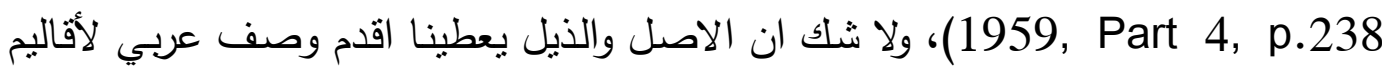

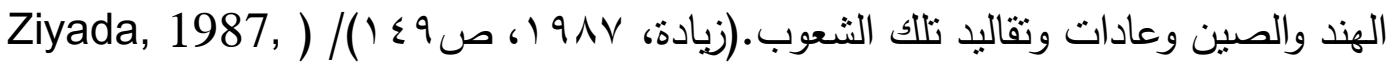
p.149) وما يميز الكتاب (رحلة السيرافي) انه اقتصر بالحديث عن بلادِ الهند والصين،

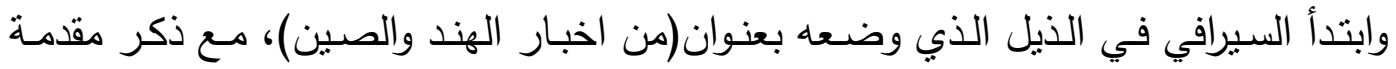

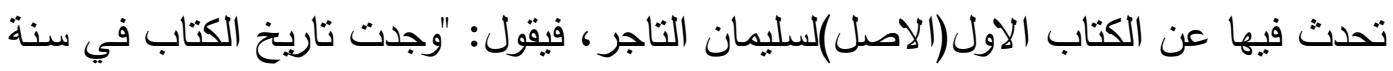

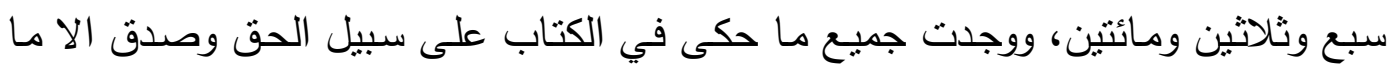

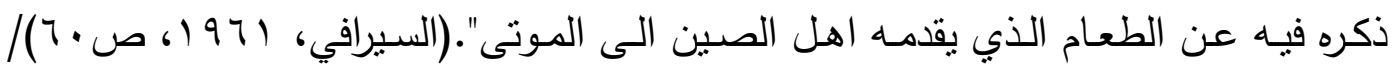
(Al-Serafi, 1961, p.60)

ثم تحدث السيرافي عن طرق تجارة سفن اهل الصين، والعقوبات التي يستخدها الصين على اصحاب الذنب وطريقة معاقبتهم، كذلك ذكر بعض حرف الصبن ووصفهم بانهم احذق

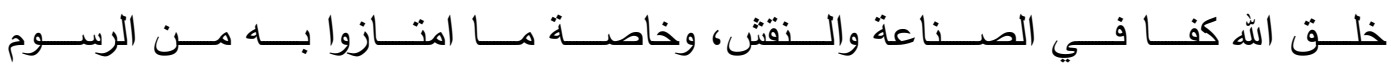

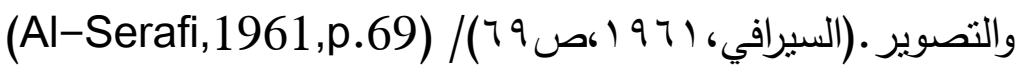
ثم ينتقل الى بلاد الهند وتحديداً الى مدينة الزايج، واصفاً اياها بالمدينة التي تحاذي بلاد

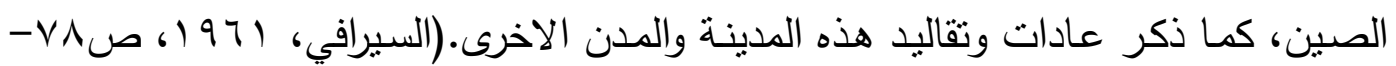


(Al-Serafi, 1961, p.78-79) / و وقد تم نشر هذه الرحلة وذيلها بعض المستشرقين

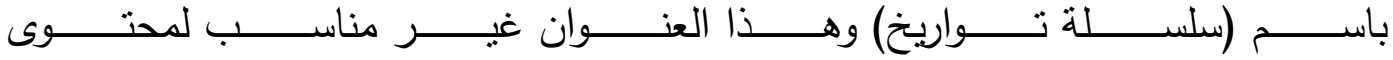

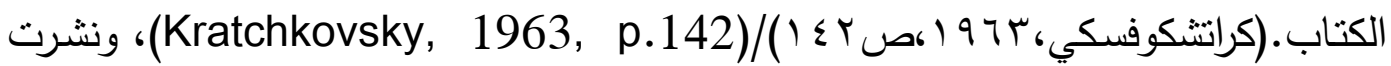

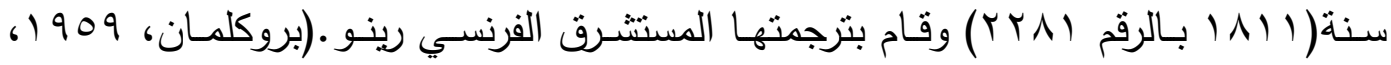

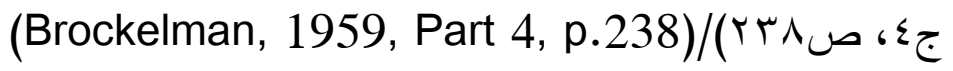
r ابن الققيه/البلدان:

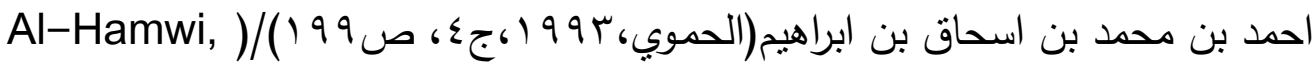

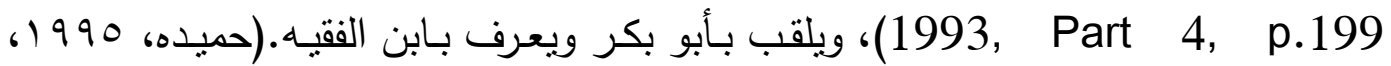
ص آب ()/ (Hamidah, 1995, p.131)، من اسرة اشتهرت بعلم الحديث والادب وهو

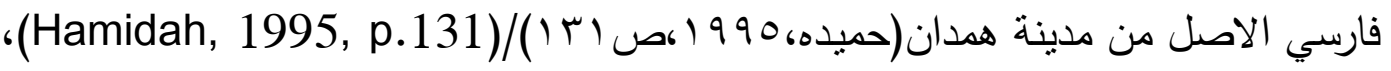
ويذكر ابن النديم لا توجد عليه معلومات وفيرة اكثر من انه من اهل الادب.(ابن النديم،

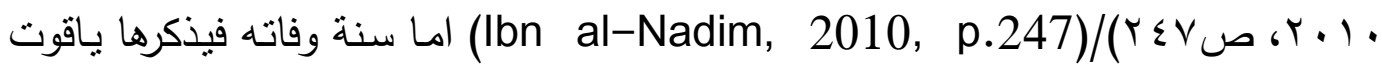

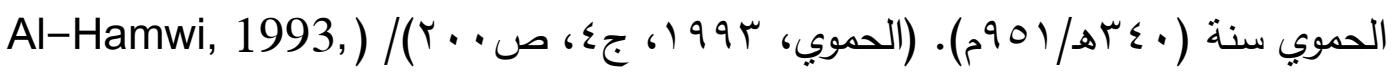

(Part 4, p.200

\section{وصف الكتاب ومنهجهُ}

دون ابن الفقيه في كتابه (البلدان) رحلاته فوصف فيـه الارض والبحـار في الصين

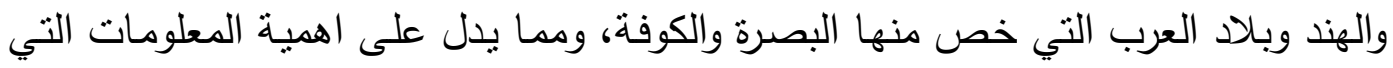

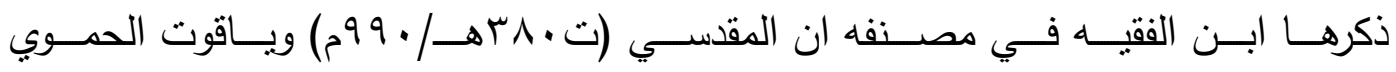

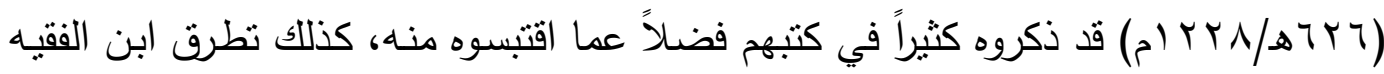

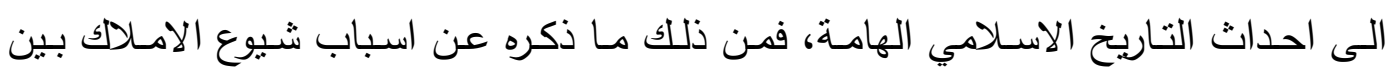

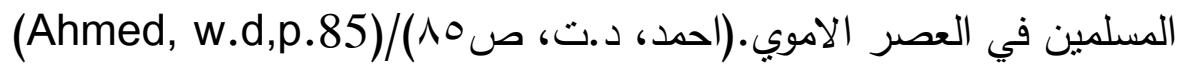

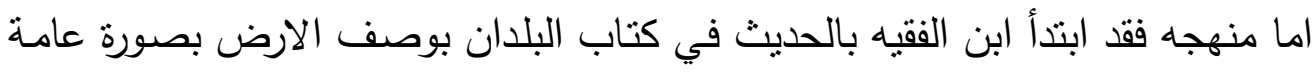

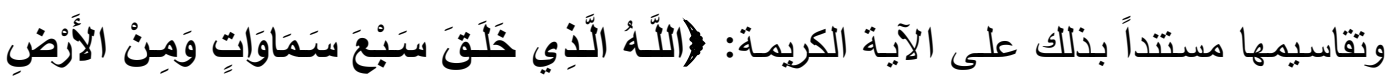

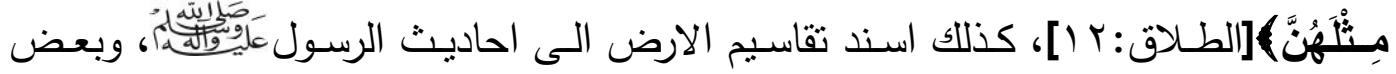

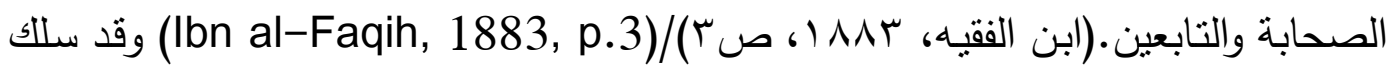
ابن الفقيه في تعريف الاقاليم المنهج الاقليمي الوصفي اي المنهج الجغرافي الصرف الذي الذي

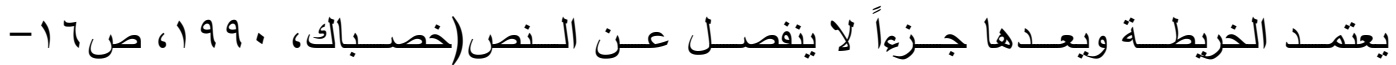

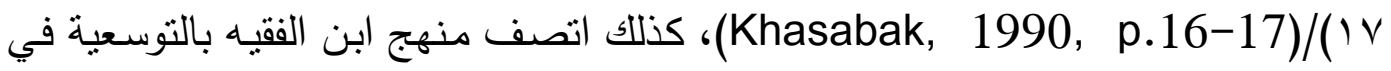

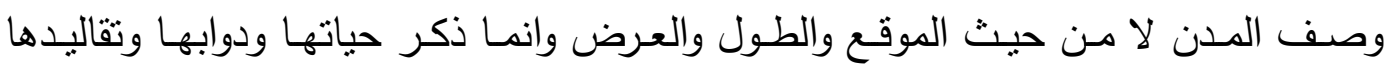

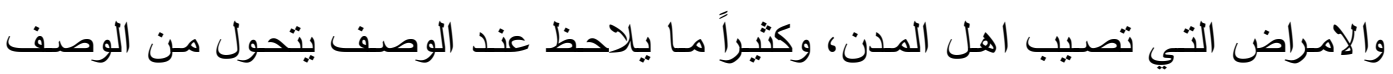


الجغرافي الى الوصف الاجتماعي للمدن فيورد على سبيل المثال عن اهل العراق: "هم اهل

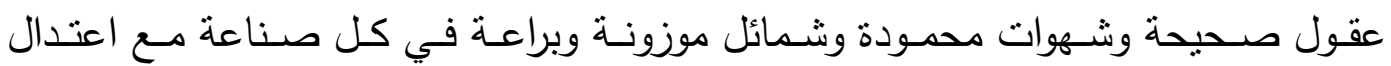
الاعضاء واستواء الاخلاط وسمرة الالوان وهم الذين انضجتهم الارحام فلم تخرج بين اثنقر

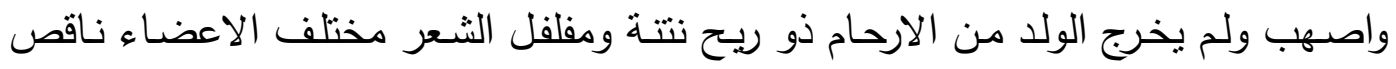

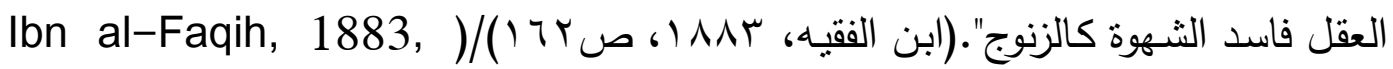
(p.162

استخدم ابن الفقيه في منهجه معاني ومدلولات المدن اعتماده بذلك على روايات تتسب

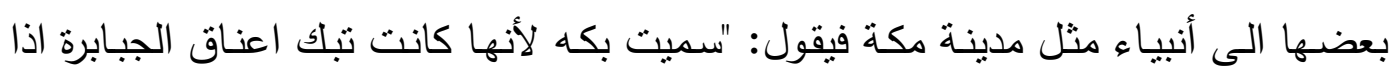

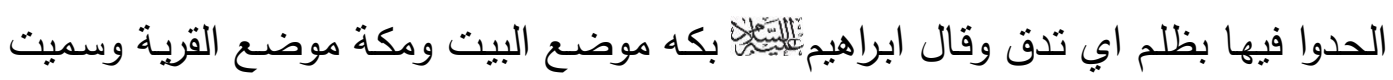

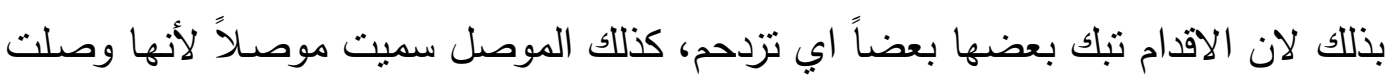

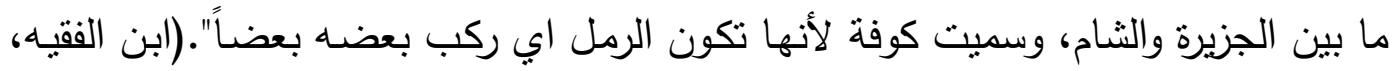

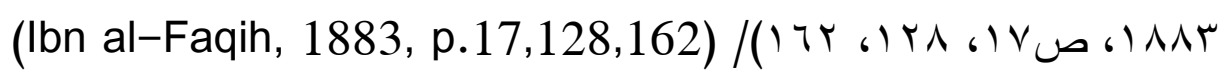
اما عن بلادٍ الهند والصين فقد ابتدأ بذكر الطرق المؤدية الى تلك البلدتين عبر البحار

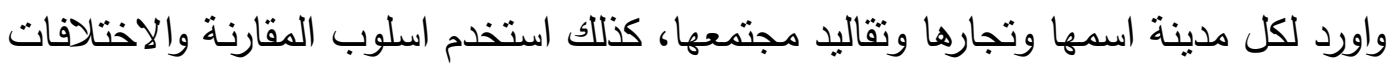

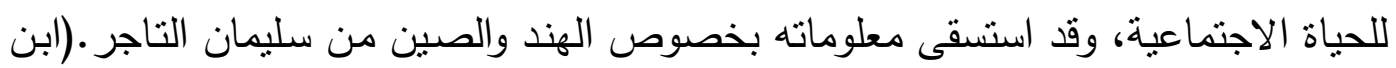

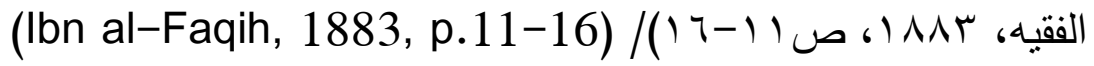
ولم يخلُ منهجه من ذكر العجائب والاساطير، فيذكر عن بعض عجائب البحار ومنها

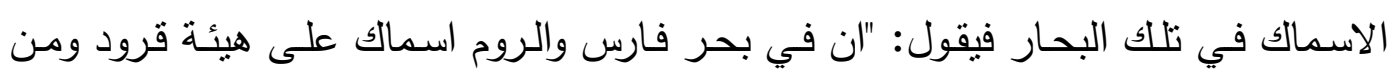

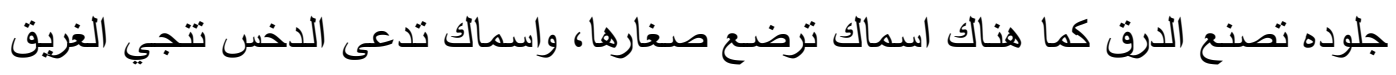

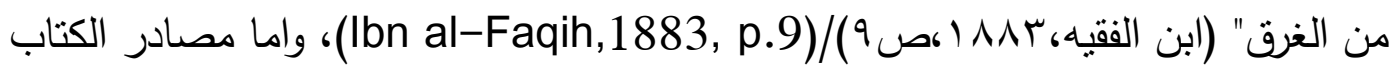

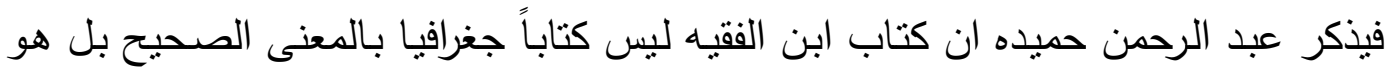

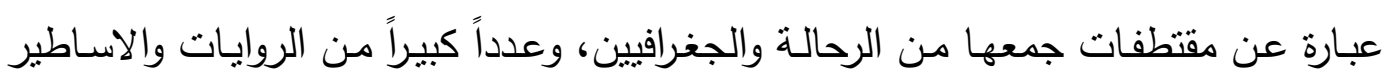

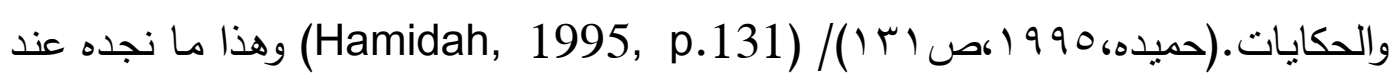
ابن الفقيه عندما يشير الى عدد من الرحالة والجغرافيين منهم سليمان التاجر وابن خرداذبة والجاحظ والبلاذري.

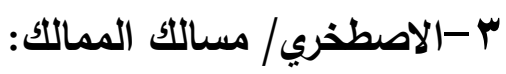

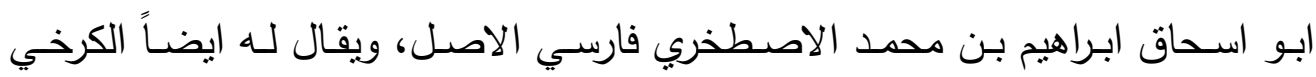

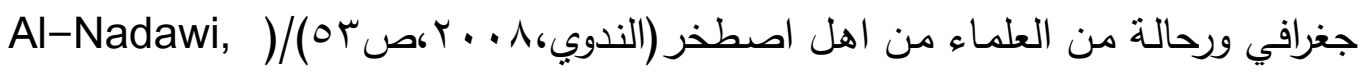

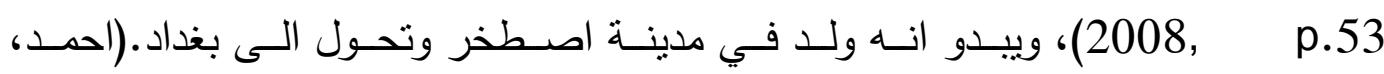
(Ahmed, w.d, p.80)/(^.ت، د. 
اجمـع المؤرخـون ان الاصـطخري مـن رحالـة وجغرافيّ القـرن الرابـع الهجري/العاشـر

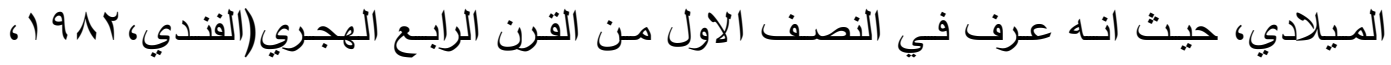

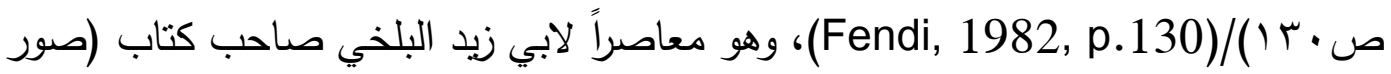

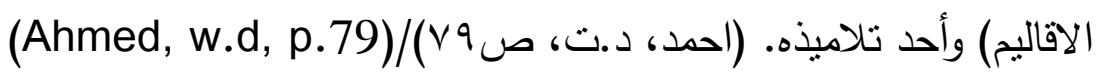

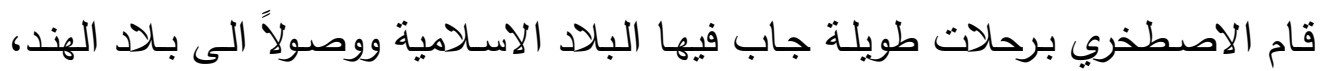
وقيل عند وصوله الى بلاد الهند التقى بثاب يدعى ابن حوقل وهو المؤرخ المعروف، وكان

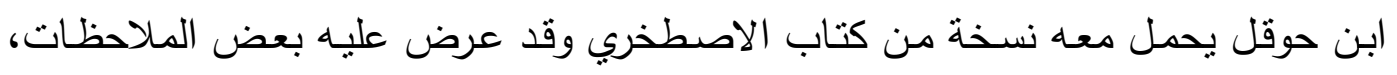

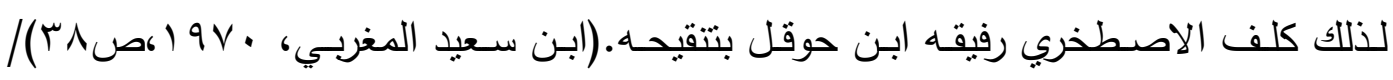
(Ibn Saeed Al-Maghrabi, 1970, p.38)

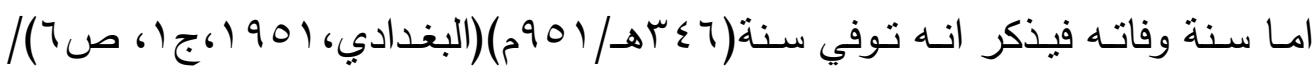
Zarkali, )/(الزركلي، r) (Al-Baghdadi, 1951, Part 1, p.6) .(2002, Part 1, p.61

\section{وصف الكتاب ومنهجةُ}

اقتصر الاصطخري كغيره من الجغرافيين على وصف العالم الاسلامي وحده، مقسماً اياه الى عشرين اقليماً، كذللك اورد ابعاد البحار ووصف جزيرة الجيرة العرب وبحر فارس والمحيط

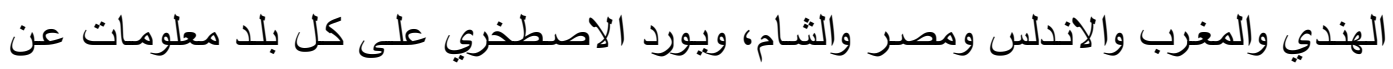
الحدود والمدن والمسافات وطرق المواصلات ويروي تفاصيل متفرقة عن التجارة والصناعة

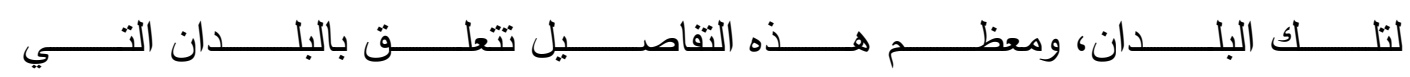

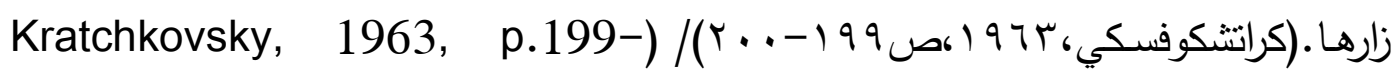

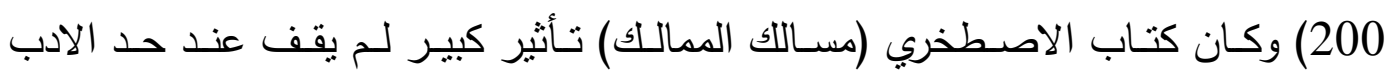
الجغرافي وقد كتب في الاصل باللغة الفارسية، وقيل انه كتب بالعربية وترجم الى الفارسية التية

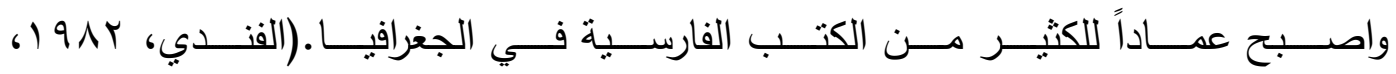
(Fendi, 1982, p.130)/() ص. (1)

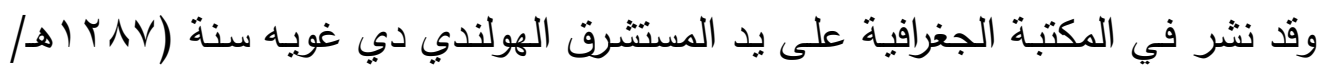

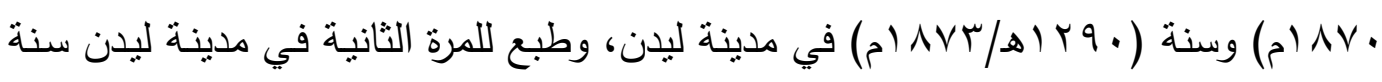

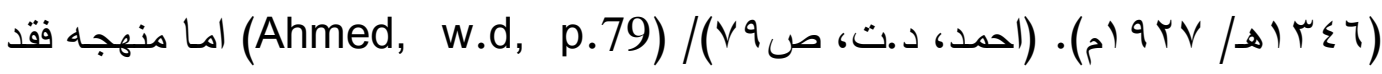

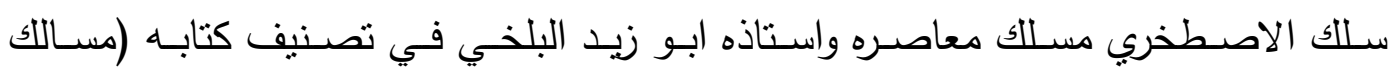

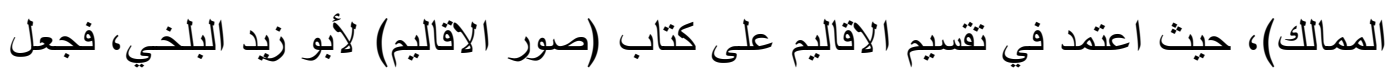

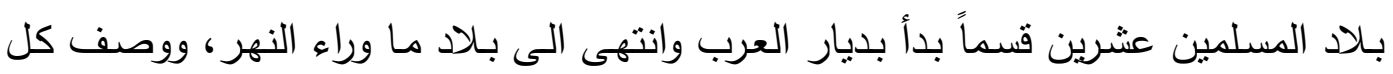


قسم على حده، مع ذكر للبلاد والمدن وتجارتها ومزارعها وصناعتها وحرف اهلها. (حميده، (Hamidah, 1995, p.199)/(1999 (1990 ولكن قام الاصطخري بتوسعة كتابه كثيراً وصحح الكثير ممـا جاء فيه، كما امدهاه بالخرائط، وقد فصل لنا في مقدمة كتابه اسلوبه ومنهجه فقال: "اني ذكرت في كتابي هذا اقاليم الارض على الممالك، وقصدت منها بـلاد الاسـلام بتفصيل مدنها وتقسيم مـا يعود بالأعمال المجموعة اليها. ولم اقصد الاقاليم السبعة التي عليها قسمة الارض، بل جعلت كل قطعة افردتها مفردة مصورة تحكي موضوع ذلك الاقليم"، ثم يضيف ويقول: "فقصلت بلاد

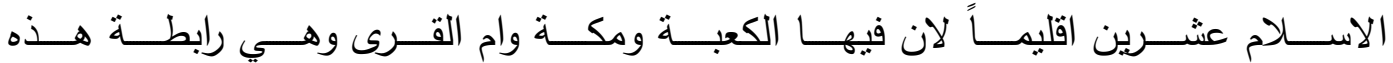

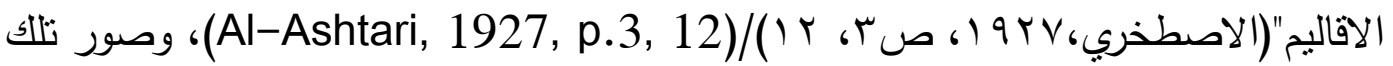
الاقاليم، في اختصار ولم يسهب في الوصف والكلام لأنه كما يقول: "الاسهاب في الكلام الذي يؤدي الى ملل القراءة، وغرضي تصوير هذه الاقاليم، اما ذكر المدن والجبال والبحار

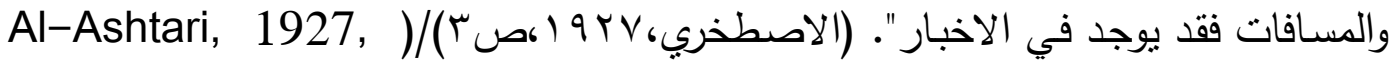
(p.3 ولعل من اهم مميزات كتاب (مسالك الممالك) هو مقارنة المدن ببعضهها اي ترك الآل تحديد المسافات واللجوء الى نسبة المدن والبلاد ببعضها البعض رغبة منه في الاختصـار

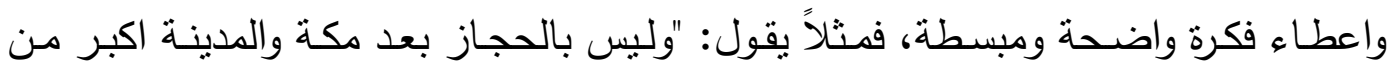
اليمامة ويليها في الكبر وادي القرى والجار ميناء الددينة بيد ان جدة ميناء مكة وليس بعد

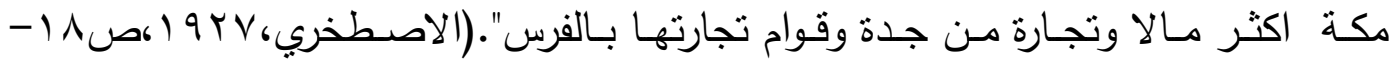
(Al-Ashtari, 1927, p.18-19)/(19

امـا مـا اورده عن بـلاد الهند والصين، فقد اعطى لبلاد الهند باباً وجعلها ضمن اقليم السند من حيث الوصف بقوله: "واما بلاد السند وما يعاقبها مما قد جمعناه في صورة واحدة

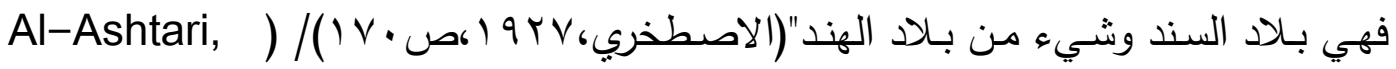
1927, p.170)، وفيما يخص بلاد الصين فقد اثشار بمقتطفات بسيطة الى تلك البلاد

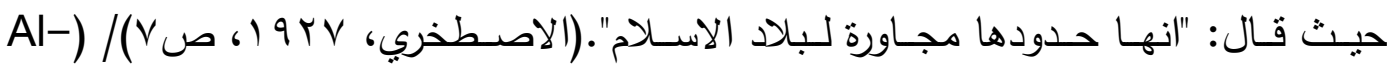

(Ashtari, 1927, p.7

\section{ع -المسعودي/مروج الذهب ومعادن الجوهر :}

علي بن الحسين بن علي ابو الحسن المسعودي المؤرخ، من ذرية الصحابي عبد الهه

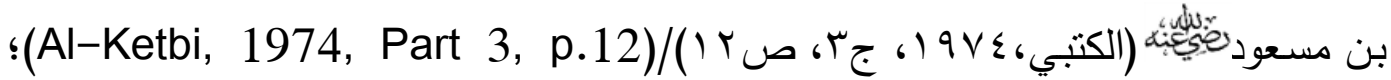

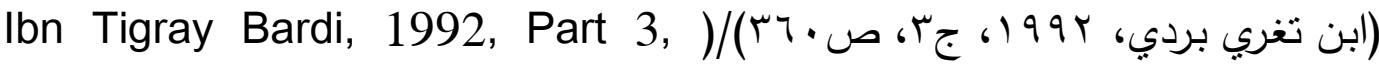




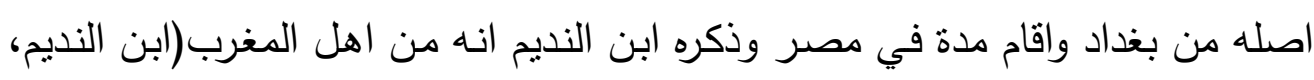

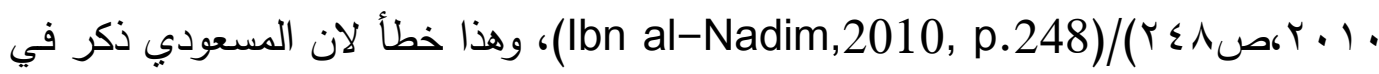
السفر الثاني من كتاب (مروج الذهب)عدد فضائل الاقاليم ووصف هوائها واعندالها وانحرافها

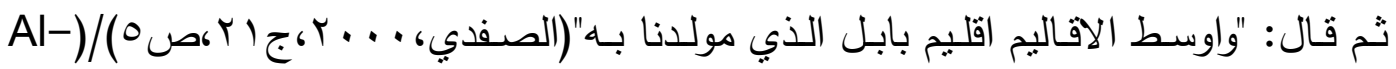

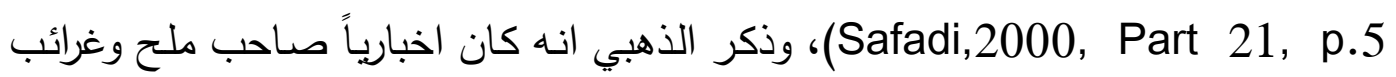

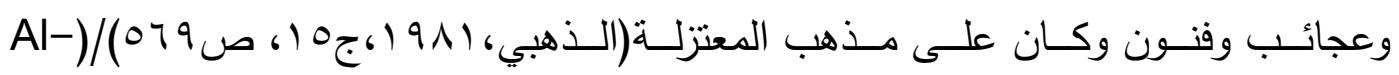

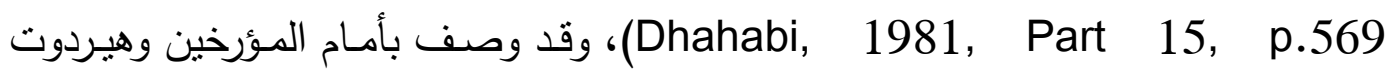
(العرب.(احمد، د.ت، ص ا • (1)/ (Ahmed, w.d, p.101)

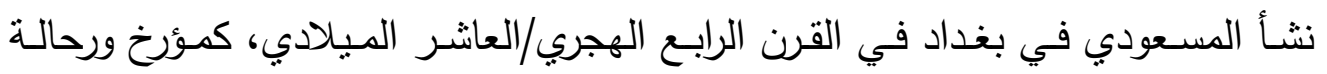

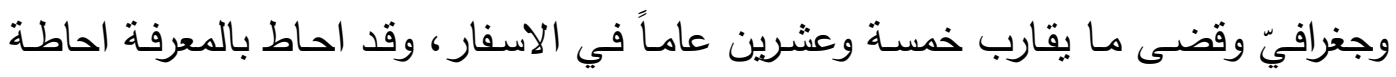

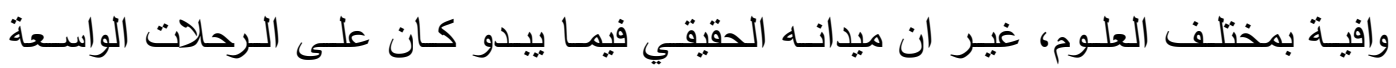

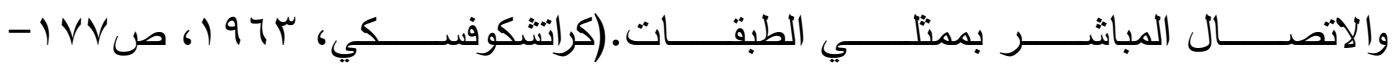
(Kratchkovsky, 1963, p.177-178)/( / VA

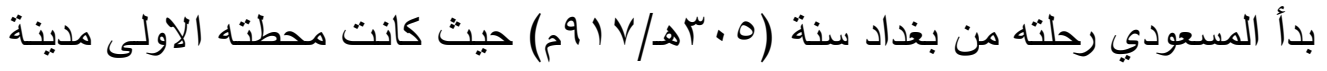

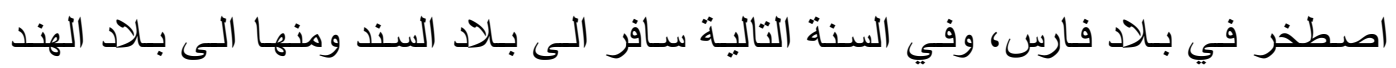

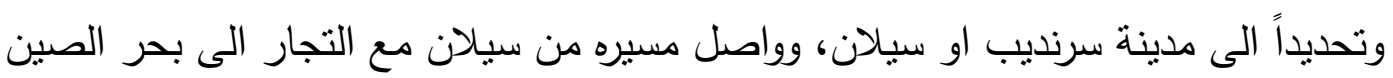

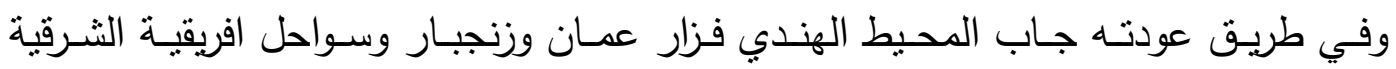

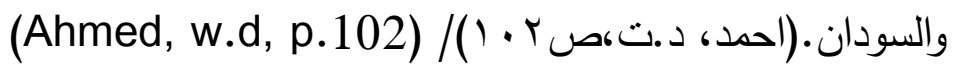

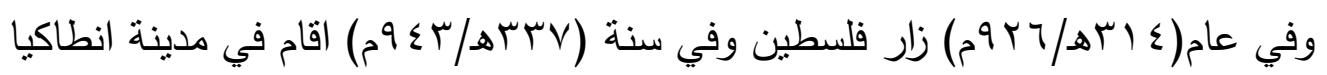

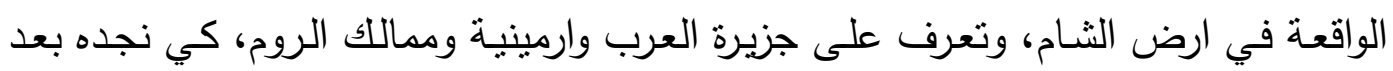

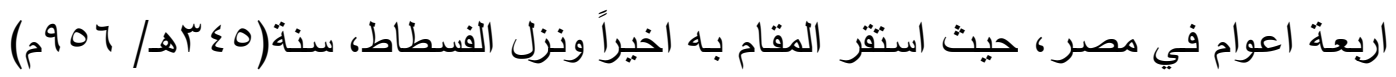

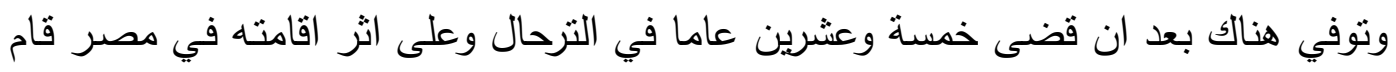

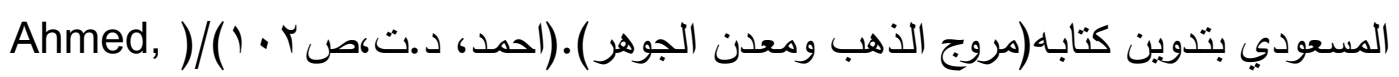
(w.d, p.102

ولم يكن المسعودي رحالة يحب الاستطلاع فحسب، بل كان ايضاً عالماً يتمتع بمرونة

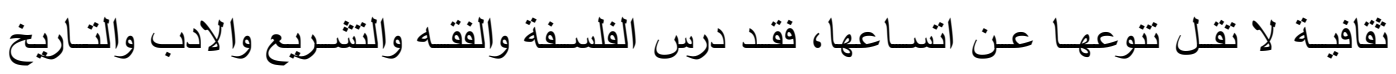

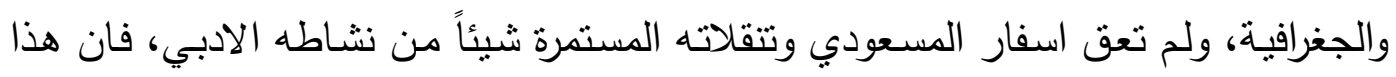

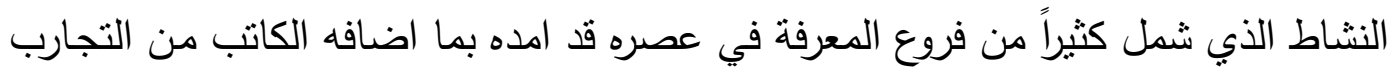
Ibn Saeed

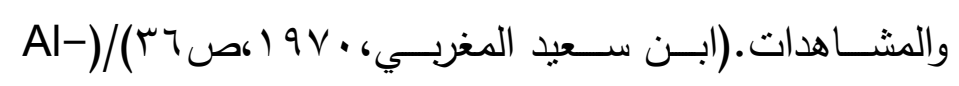
(Maghrabi, 1970,p.36 


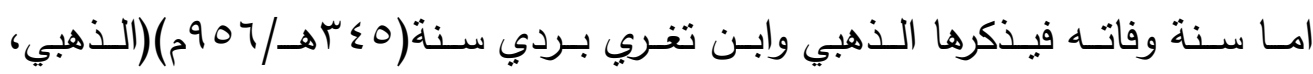

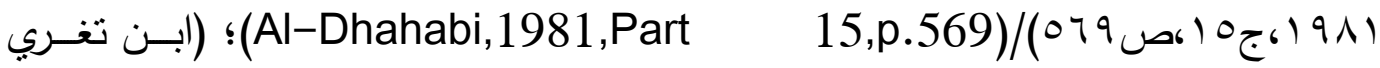

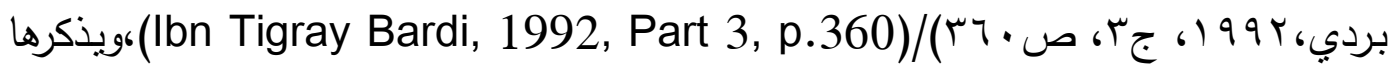

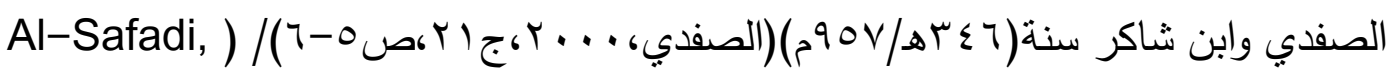

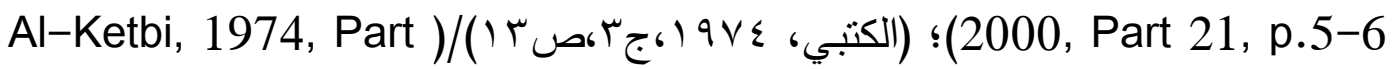
وصف الكتاب ومنهجةُ

كتاب(مروج الذهب ومعادن الجوهر ) مصنف تاريخي جغرافي عظيم القيمة لم يكتفي فيه المسعودي ببحث الموضوعات التي اعتادها المؤرخين المسلمين، بل تطرق الى تواريخ الهند

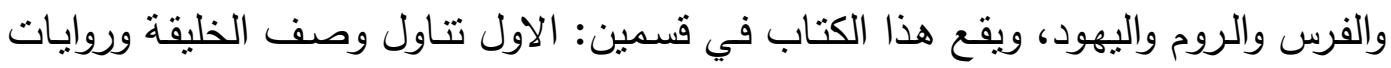
قصص الانبياء في ايجاز ، ثم انتقل في وصف ولتف الارض والبحار والعجائب والغرائب وتاريخ الامم القديمة وما كانت تعتتقه من الاديان وما تعتقد فيه من المذاهب وما تتبعه من العادات والتقاليد، ثم عرض للأيام والثهور والثقاويم وكل ما يتعلق بذللك، اما القسم الثاني من الكتاب نابن

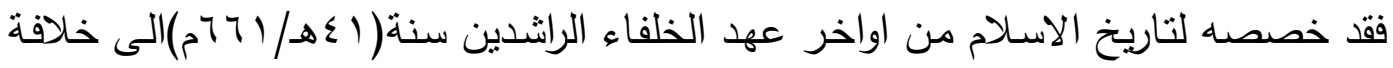

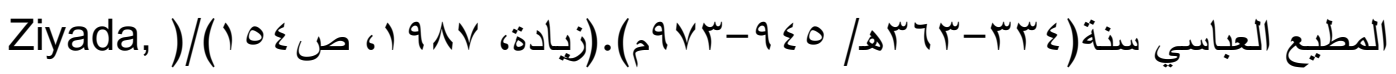
(1987, p.154

وقد بين المسعودي في مقدمة كتابه (مروج الذهب) اغراض هذا الكتاب قائلاً: "اما بعد

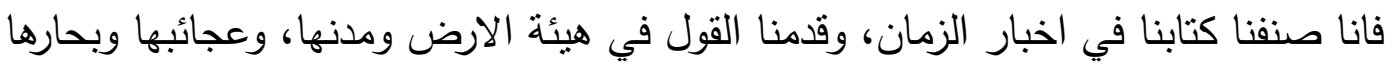
واغوارها وجبالها وانهارها وبدائع معادنها، واصناف مناهلها واخبار غياضها، وجزائر بحارها،

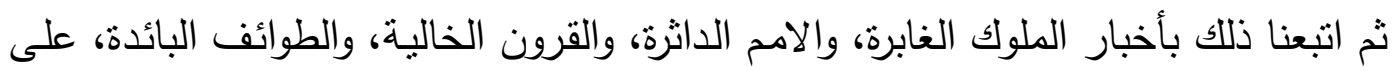
مر سيرهم، في تغيير اوقاتهم وتصنيف اعمـارهم، مـن الملوك الفراعنـة العاديـة والاكاسـرة

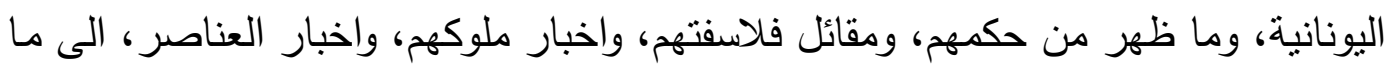

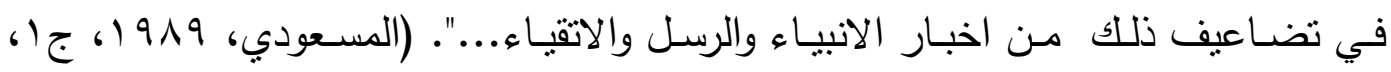

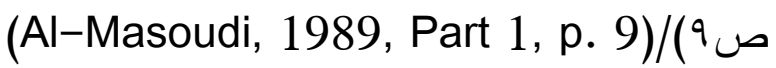
ويعتبر كتاب (مروج الذهب) من المؤلفات الضخمة للمسعودي التي فقد اغلبها، حيث

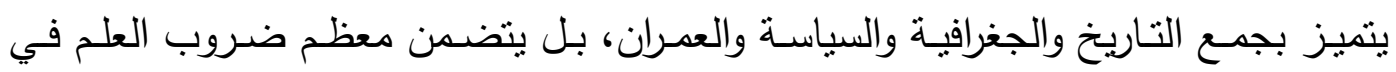

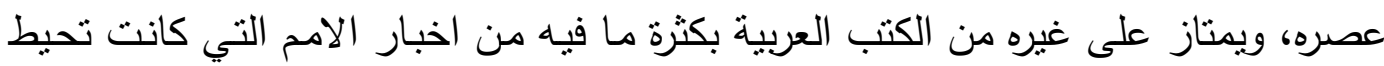
بالعالم الاسلامي في العصور الوسطى، وبندرة بعض هذه الاخبار في كتب سائر المؤلفين،

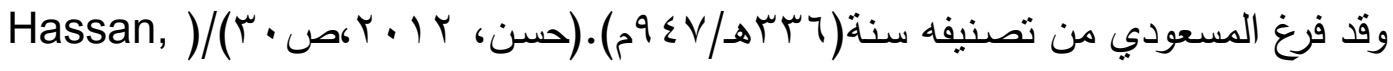


كذلك اعتبر هذا الكتاب من المؤلفات التاريخية والجغرافية التي تعطي صورة واضحة على البلدان وما فيها، وما ميز هذا الكتاب انه لم يتعرض لضياع او الفقدان(كراتتكوفسكي،

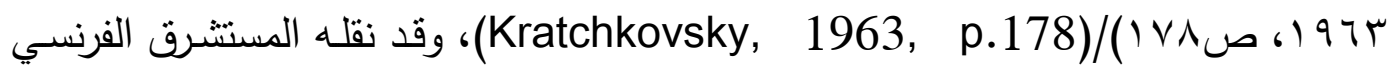
باربيه دي مينار الى الفرنسية وطبع في باريس في تسعة مجلدات سنة (

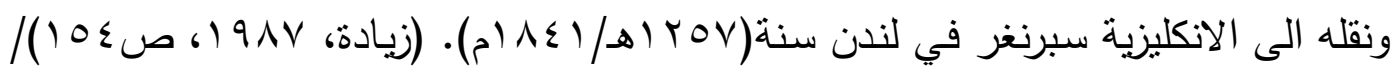
(Ziyada, 1987, p.154) اما منهجه فقد ذكر المسعودي في مقدمة كتابه قائلاً: "انا نعتذر من تقصير ان كان، ونتصل مـن اغفال ان عرض، لمـا قد شـاب خواطرنـا، وغمر قلوبنا، مـن تقاذف الاسفار ، وقطع الفقار، تارة على منت البحر، وتارة على ظهر البر مستعملين بدائع الامم بالمشاهدة،

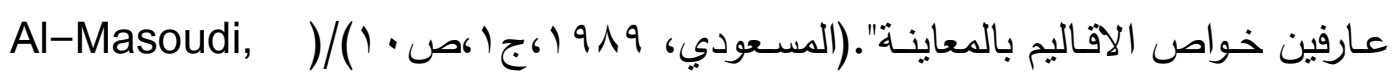
(1989, Part 1, p.10 لا يأخذ المسعودي على عاتقه التصدي للجغرافيين ومنافستهم، ابي الى اولئك الذين يصفون كل مدينـة او يقدرون كل مسـافة يقطعونها، فهو يكتب حسب اسلوب المشـاهدة العينيـة الدقيقة، والذي يجتذب بـه كل مـا هو مستخرب، والذي يتفحص كل مـا يقع تحت بصره، ولا تفوته فرصـة الاستفسـار من الثخصيات البارزة او زيارة الذين يرددون الاقاويل والانتقادات عن مدينة ما. (مينورسكي، 910 (، صس ()/(Menorsky, 1985, p.13)

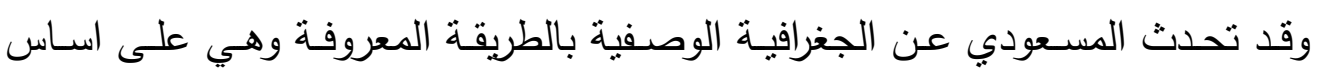

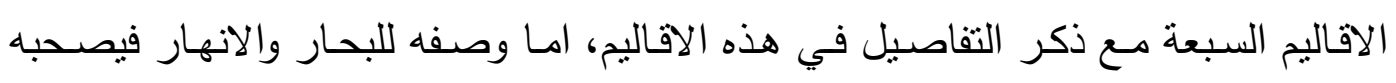
وصف دوجز للأقطار التي تجري فيها او تمسها ومن هذه الاقطار هي بـلادِ الهند والصبن، الصنا، كذلك تميز منهج المسعودي بالوصف التاريخي وقد غلب عليه هذا الطابع، ولم يقتصر في

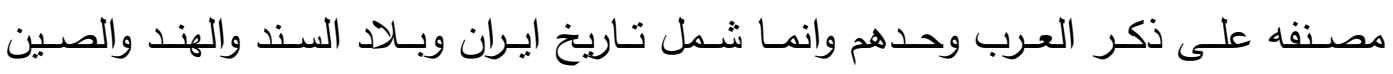

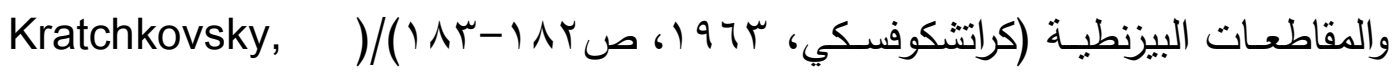
183-1963, p.182، واضاف كراتثكوفسكي ان من المستحيل انكار ما تميز بـه منهج المسـودي من تتوع النشـاط العلمي ومـا يتصف بـه من موضـوعية في الحكم فيمـا يتعلق بالثـعوب والاديان، فهو يسـأل باهتمـام ممثلي العقائد ويفحص بانتباه فائق كتبهر وبتعرف

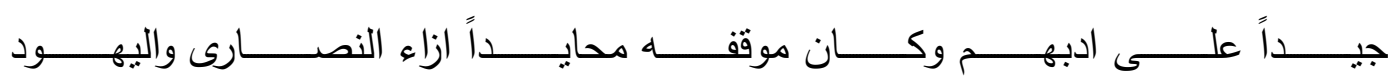

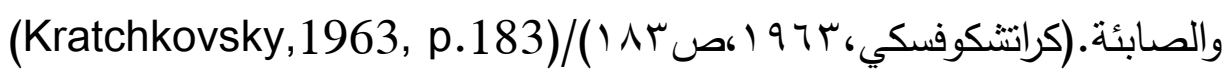
كذللك اورد المسعودي في مؤلفه بعض اوهـام المؤلفين الذين اوردوا معلومات خاطئة، ومن الامور التي عني بها هي التعليم لبعض الظواهر الاجتماعية والاقتصسادية مثل قوله: "ان العـاج كـان يجلب في كثره مـن شـرقي افريقبـة السى الصـين، وان اقبـال الصـيني على 


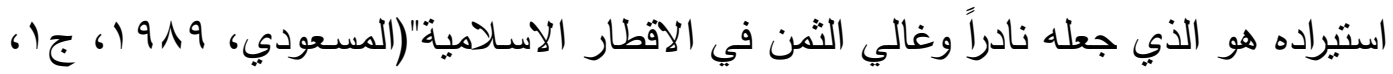

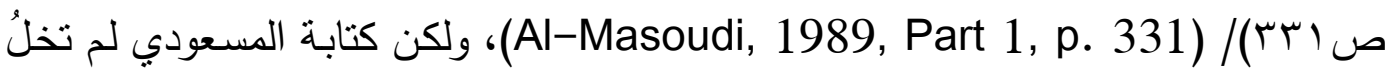
من العيوب المعهودة في تأليف بعض الجغرافيين والمؤرخين ايام العصور الوسطى ومن تلك العيوب نقل الخرافات والاسـاطير دون تمحيصها بالنقد العلمي او بـالرجوع الى المصـادر

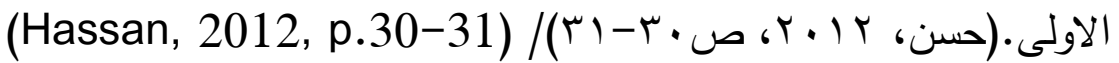

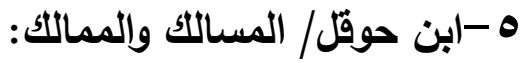

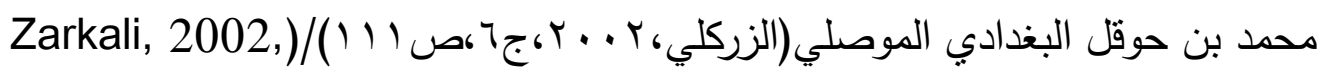

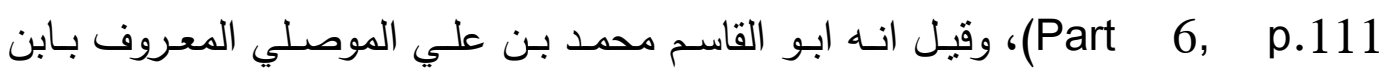

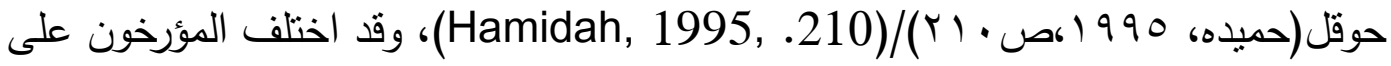
أصل ابن حوقل فمنهم دن يقول: انهه من اهل بغداد وعمل فترة مس الزمن في مدينـة

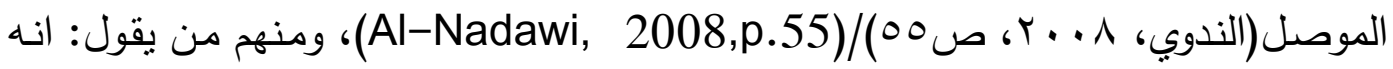

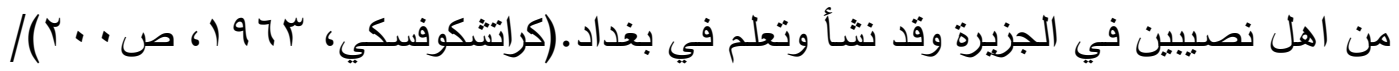
(Kratchkovsky, 1963, p.200)

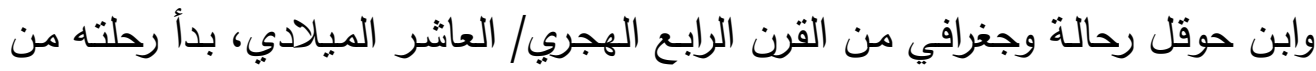

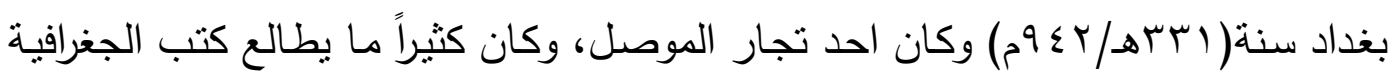

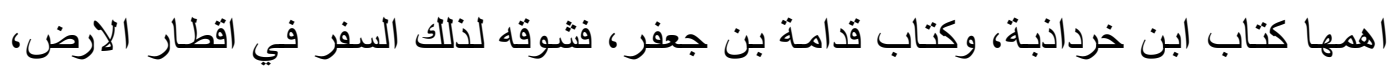

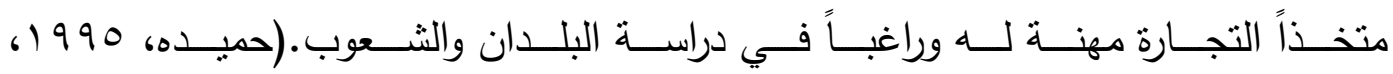
(Hamidah, 1995, p.210)/(r) ص وظل يجوب البلدان والثـعوب، فطـاف العـالم الاسـلامي مـن شـرقه الى غربـه، فزار

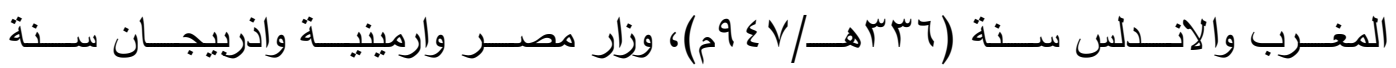

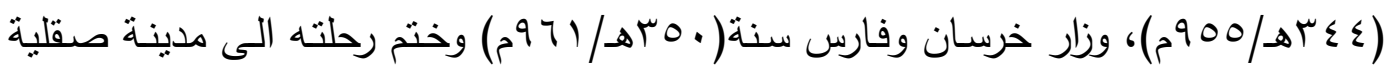

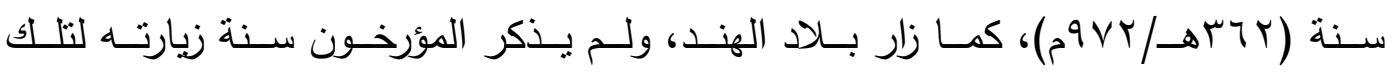

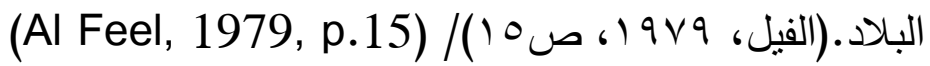
ويذكر ابن سعيد كان ابن حوقل يسعى وراء نرحاله الى تحقيق غرض مزدوج، فقد كان

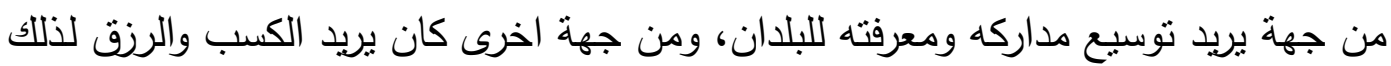

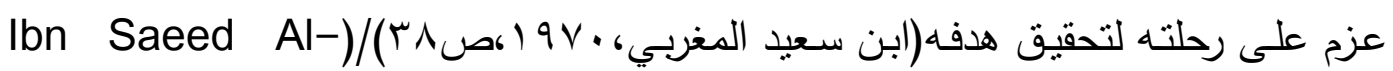

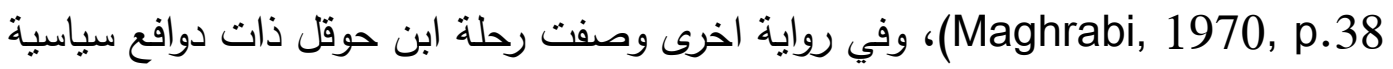

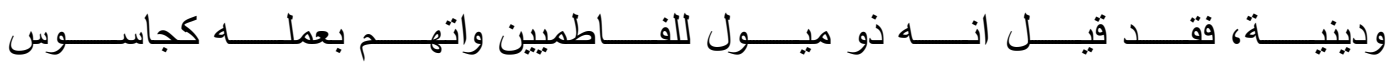

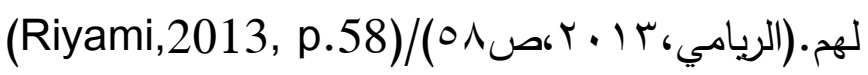


وقـد التقىى ابـن حوقـل اثتـاء ترحالـه بالاصــخري في بــلاد الهنـد، وابـدى بـبعض الماحظـات حـول كتـاب الاصطخري(مسـالك الممالك)، وقـد كلف مـن قبـل الاصـخري لتصحيح هذه الملاحظات فقبل ابن حوقل بذللك، وعلى اثر ذلك اخرج ابن حوقل كتاباً اسماه بنفس الاسم تقريباً وهو (المسالك والممالك) اعتمد فيه على ما كتبه الاصطخري.((ابن سعيد

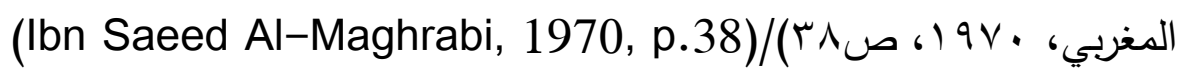
ويرى كراتشكوفسكي ان ابن حوقل اكمل عمل الاصطخري، وكان ابن حوقل اصغر منه

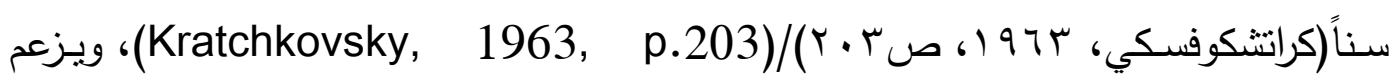

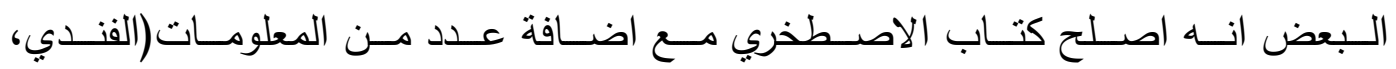

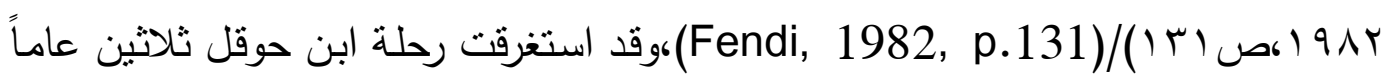

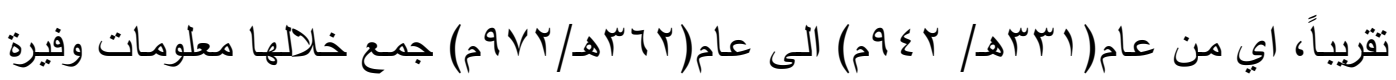

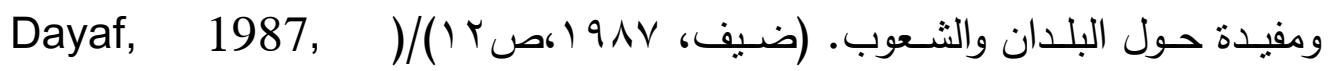

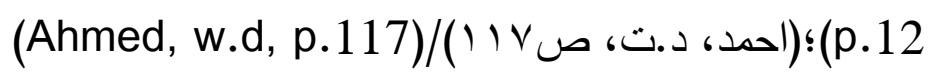
امـا سنة وفاته لم تحدد المصـادر والمراجع التاريخية سنة وفاة ابن حوقل وانما ذكرت

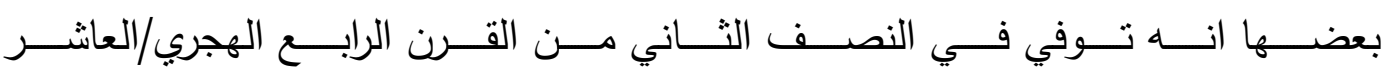

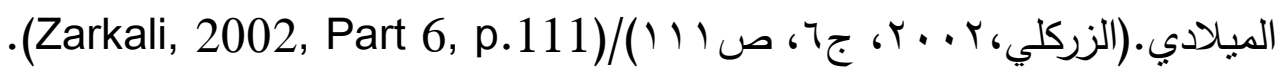
وصف الكتاب ومنهجهُ اعتبر كتاب ابن حوقل (المسالك والممالك) كتاب رحلة كبيرة في العالم الاسـلامي لا كتاب سرد جغرافي، وقد اتصف بوصف الممالك العربقة في الحضارة والتظظيم مثل بـلاد الصين والهند وفارس وبلاد الروم بالإضافة الى بلاد الاسلام، غير انه لم بتطرق الى البلدان الافريقية باستثناء النوبة والحبشة، لأنه بعتبرها بلدانا لا تملك حضارة، وهو اول كتاب وضح فيه طول الهند وعرضـها، بالإضـافة الى انه يعد اول كتاب فيه خريطة جغرافية لإقليم من اقاليم الهند، وينفرد بهذا الخصوص اي في رسم الخرائط انفراداً خاصاً فهو لا يتبع الأخرين بالوعي ولا تبصـر ، كذلك صـف مـن الموسـوعات الجغرافيـة التي وصـفت المدن والبحسار

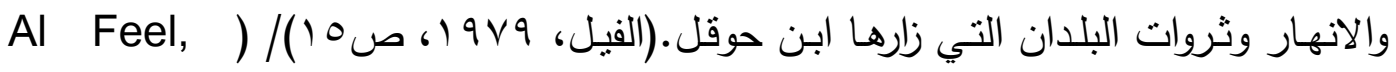
(1979, p.15

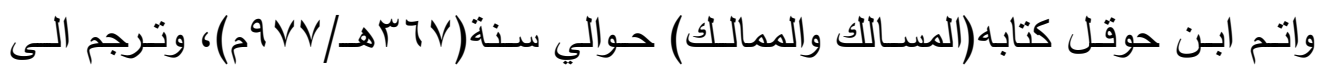

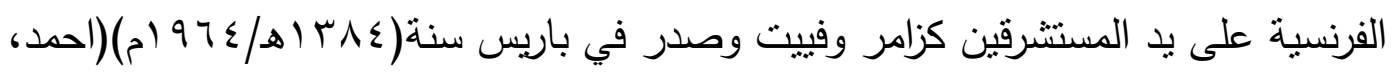
د.ت، ص/ V| ( )/(Ahmed, w.d, p.117)، وحقق على يد المستشرق الهولندي دي غوبيه

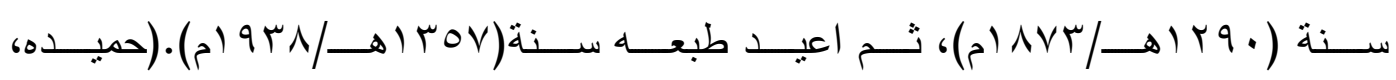
(Hamidah, 1995, p.210)/(Y) • (1) 990 


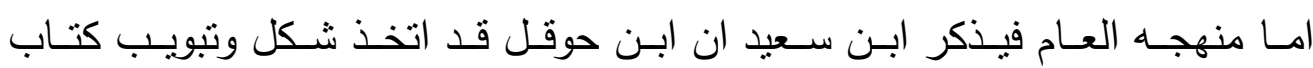
الاصطخري (مسالك الممالك) وادخل عليه تحسينات، وكانت هذه التحسينات نتشمل الفصول

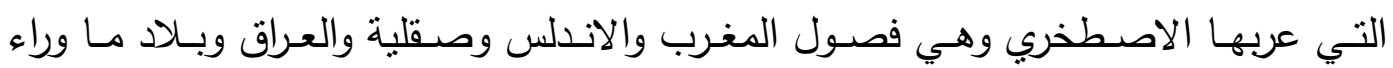

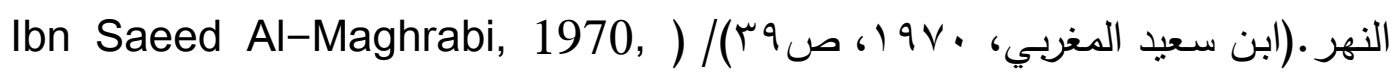

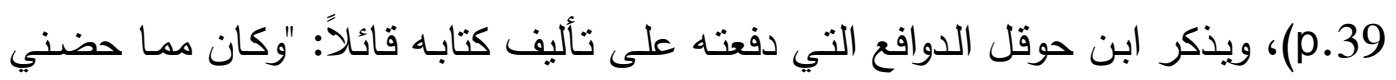

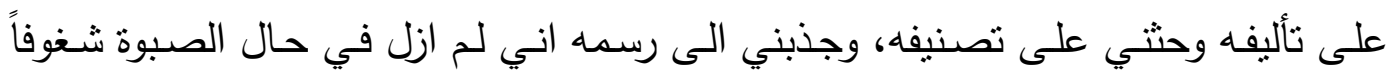
بقراءة كتب المسالك منطلعاً الى كيفية البين بين الممالك في السير والحقائق، وتباينهم في

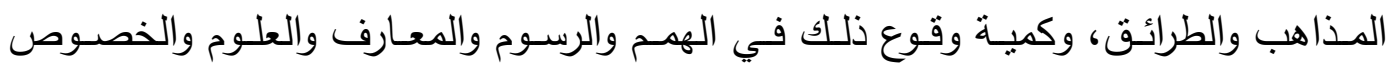
والعموم، وترعرعت فقرأت الكتب الجليلة المعروفة، والتواليف الثريفة الموصوفة، فلك ولم اقرأ في

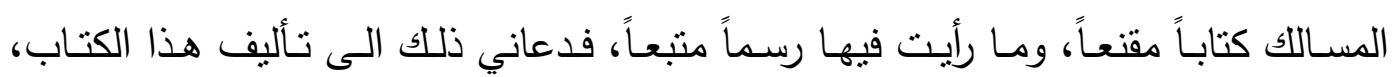
واستنطاقي فيه وجوها من القول والخطاب، واعانني عليه تواصل السفر وازعاجي عن وطني

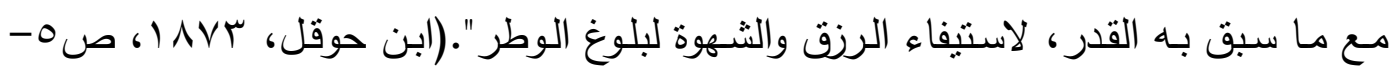
( Ibn Hawqal, 1873, p.5-6)/(7

ثم يتحدث عن ذكر البلدان وتقسيماتها قائلاً: "وقد فصلت بـانداد الاسـلام اقليماً اقليماً

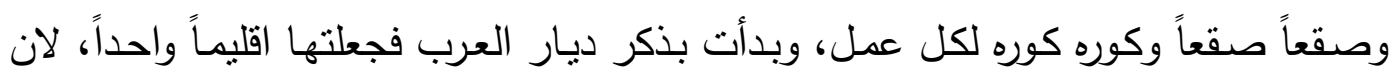

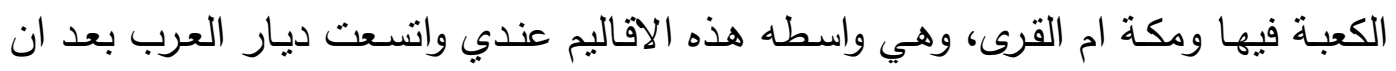

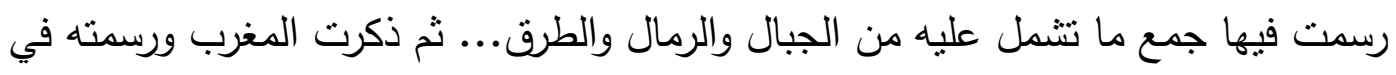

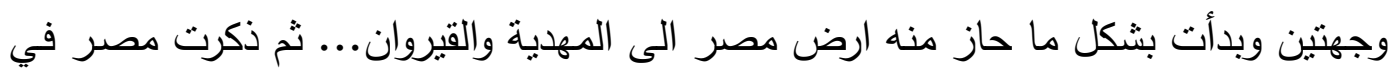

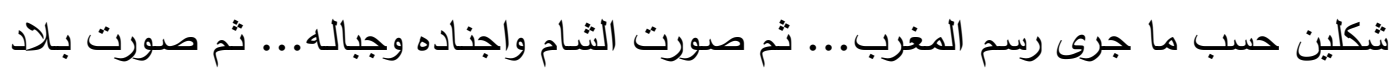

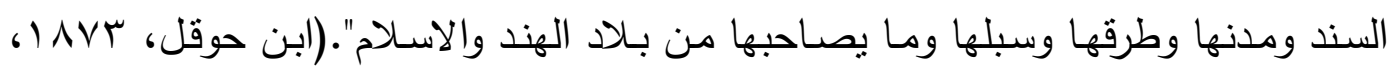
(Ibn Hawqal, 1873, p.7-14)/() ( ) (1) צ-المقدسي/احسن التقاسيم في معرفة الاقاليم:

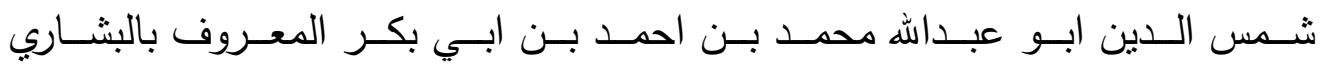

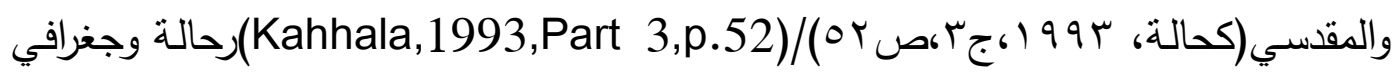

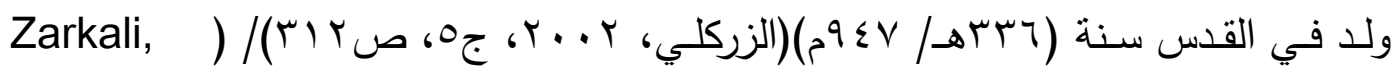

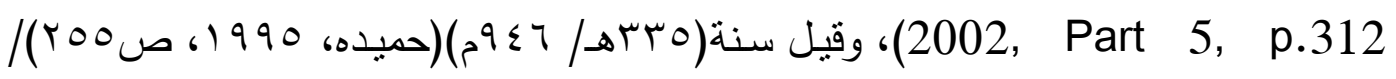

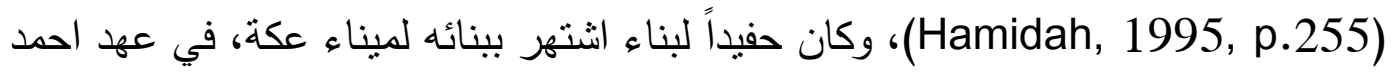

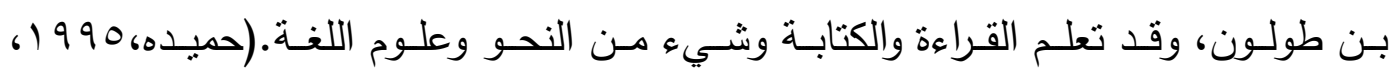

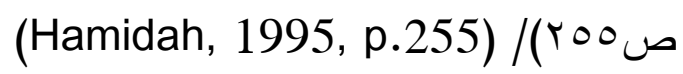




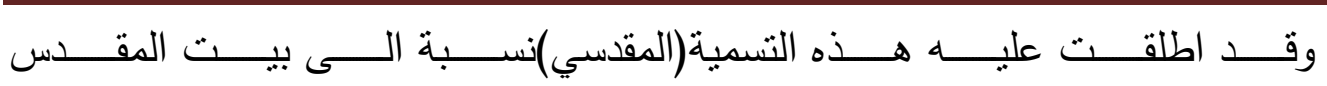

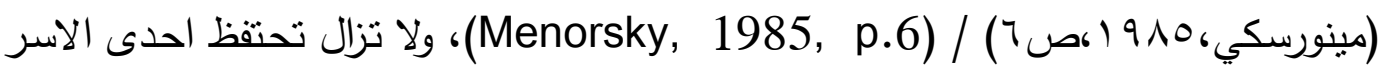
العربية بلقب المقدسي، واصل عائلته تتنسب الى قرية على مقربة من حدود خراسان وقد

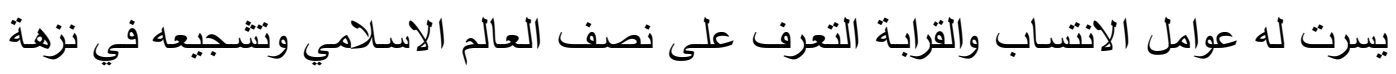

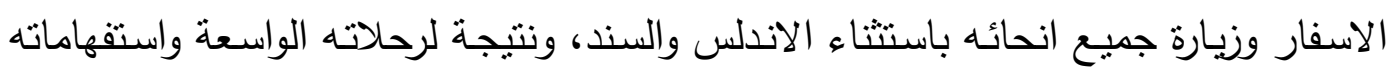

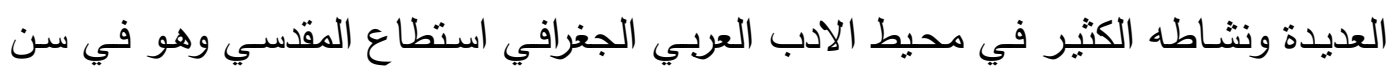

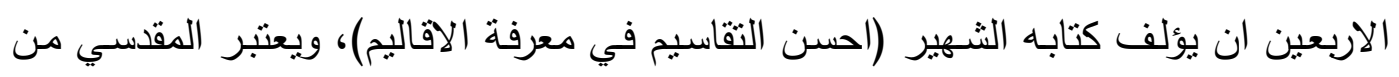

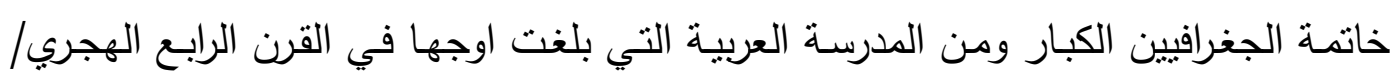

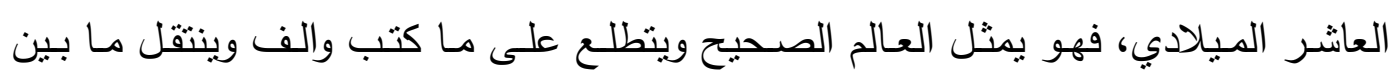

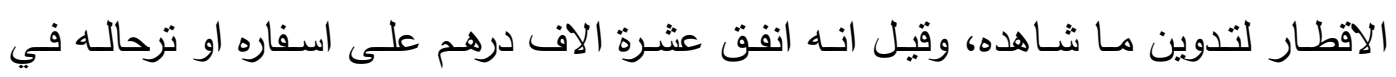

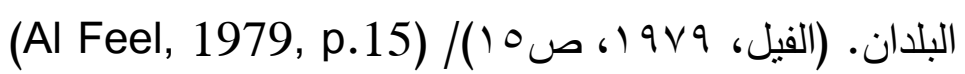

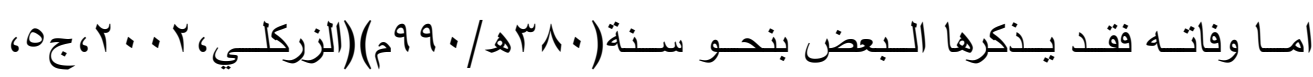

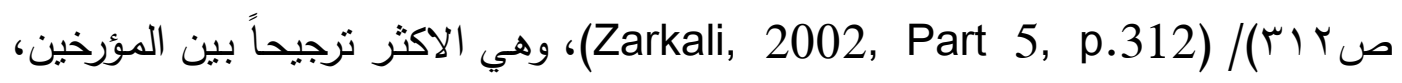

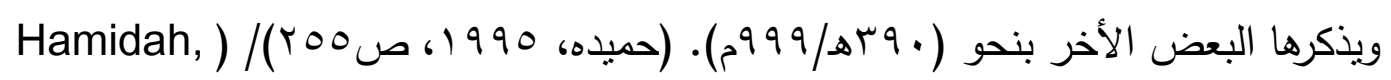

(1995, p.255

\section{وصف الكتاب ومنهجهُ}

يعتبر كتاب (احسن الثقاسيم في معرفة الاقاليم) نموذجاً للكتاب العلمي المرتب المنظم

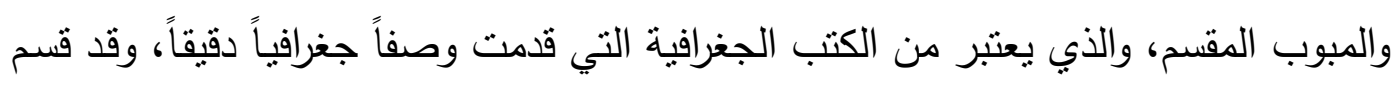

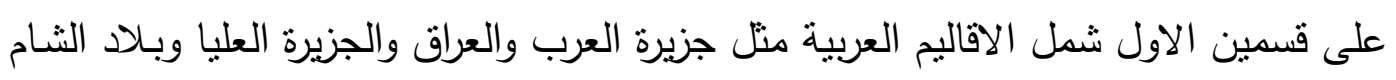

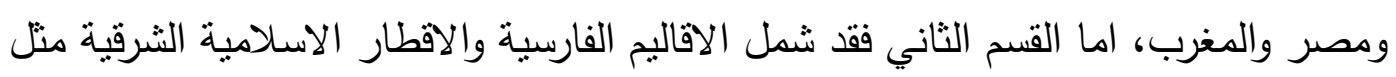

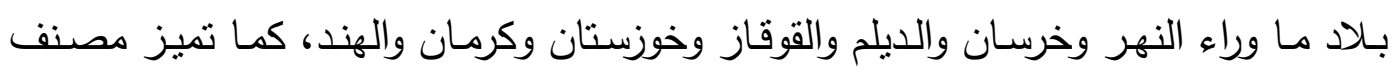

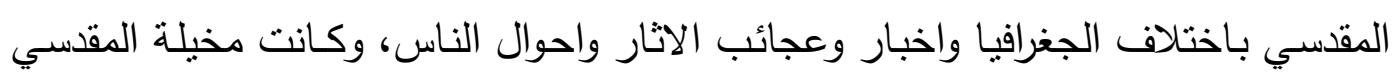

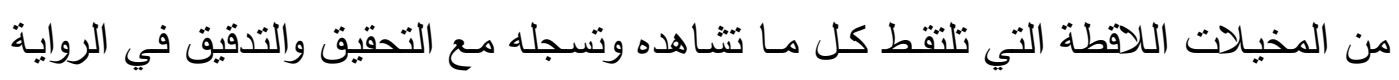

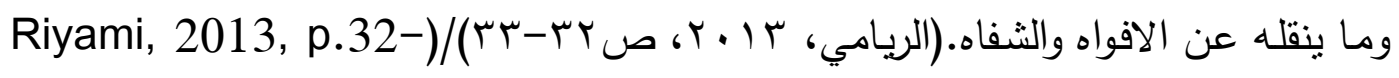

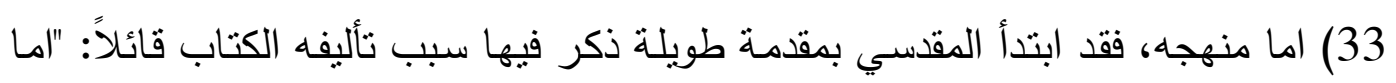

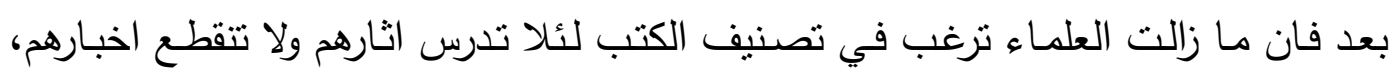

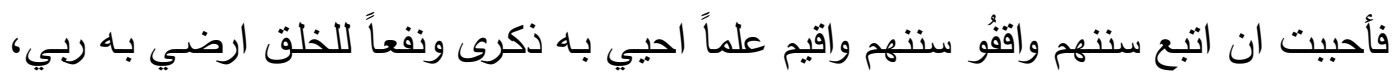

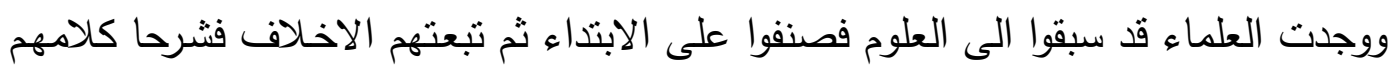

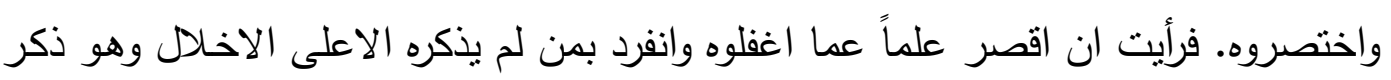


الاققاليم الاســلامية ومـا فيها مـن المفـارز والبحسار والبحيـرات والانهار ووصـف امصـارها

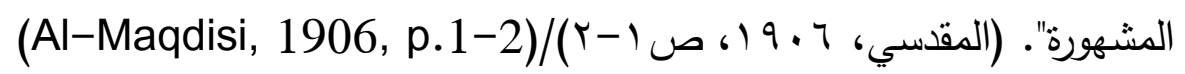

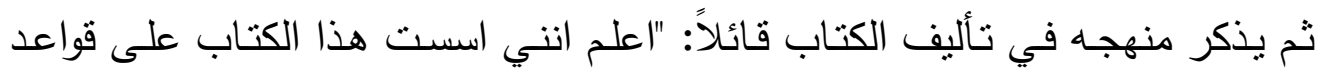
محكمة واسندته بدعائم قوية وتحريت جهدي الصواب واستعنت بفهم اولى الالباب، وسألت

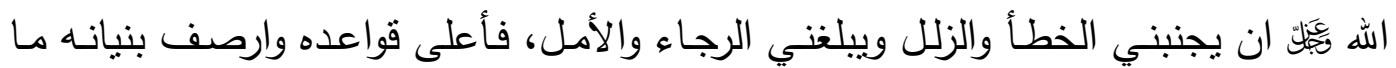

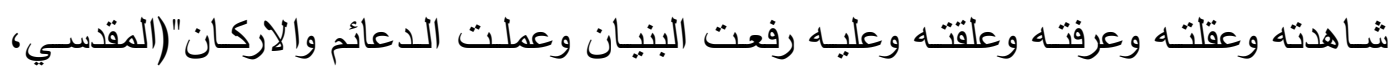

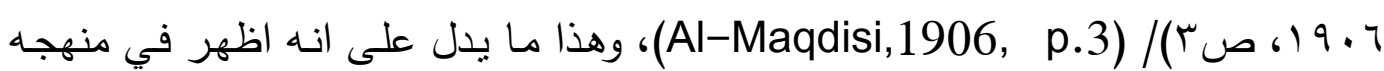
الكثثر من التمحيص والتدقيق، ثم يذكر : "ما تم لي جمع الكتاب الا بعد جولاتي في البلدان

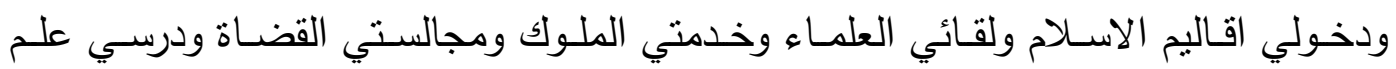

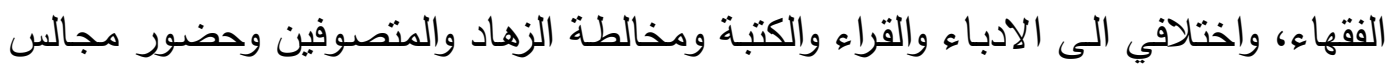

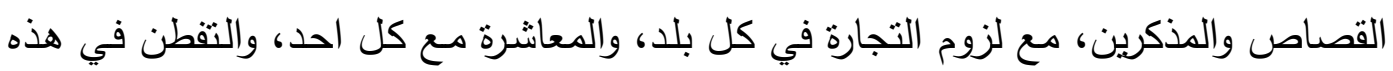

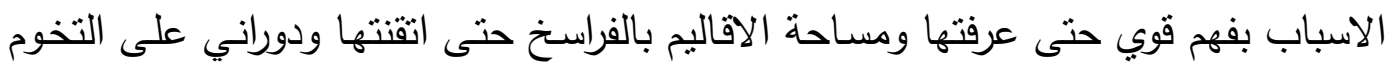

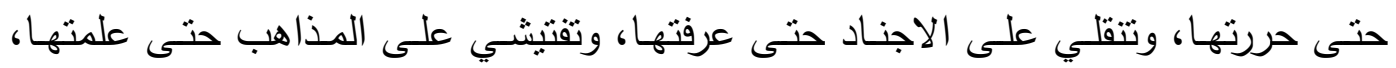

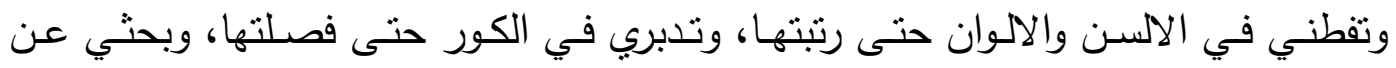

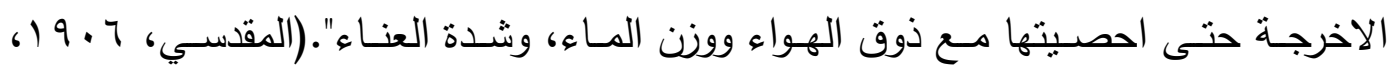
(Al-Maqdisi, 1906, p.2-3)/ ص ( وهذا الكلام يدل ابلـغ الدلالة على مدى جهده في الدراسـة، فقد عانى في جمـع مـادة

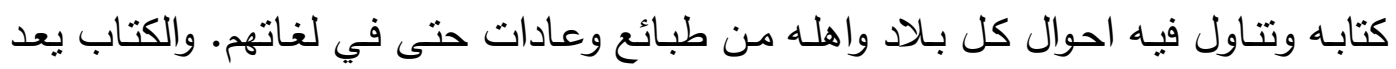



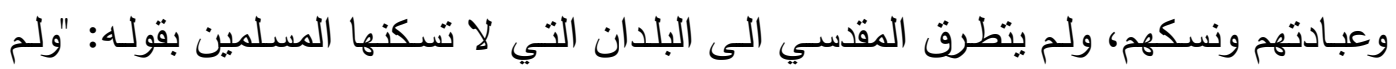

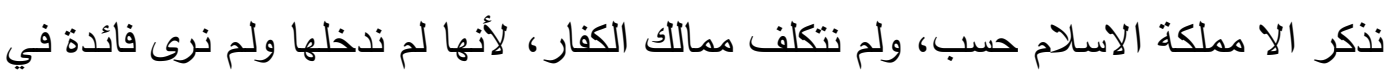

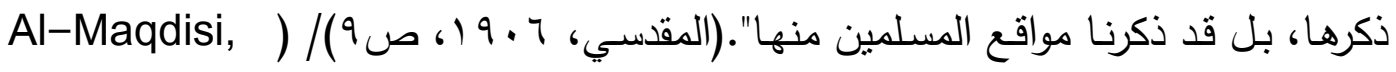

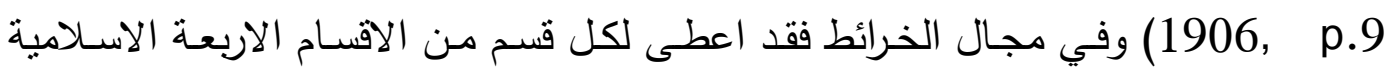

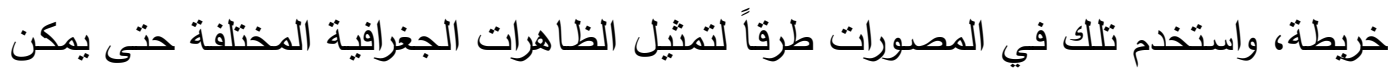

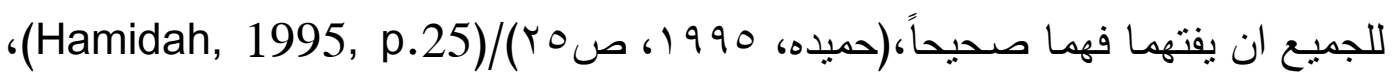

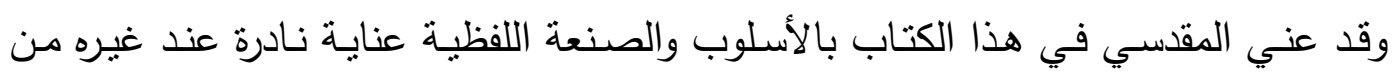

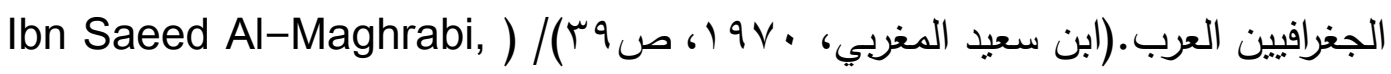




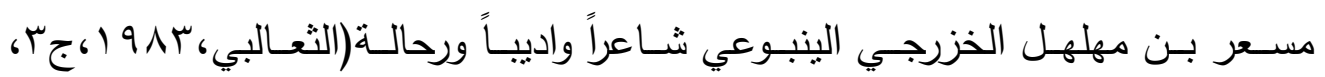

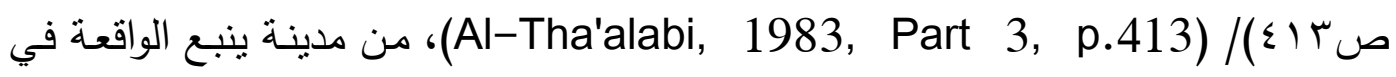

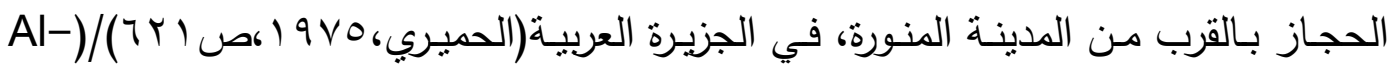
(Hamiri,1975, p.621)، ويذكر كراتتكوفسكي ان اسم مسعر بن مهابل من الاسماء

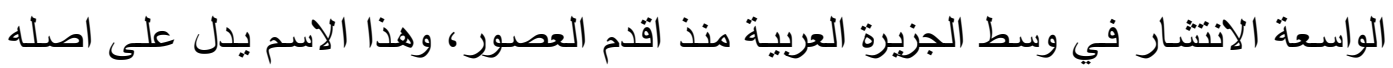

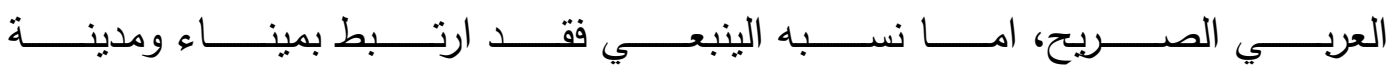

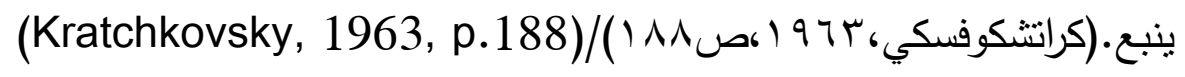

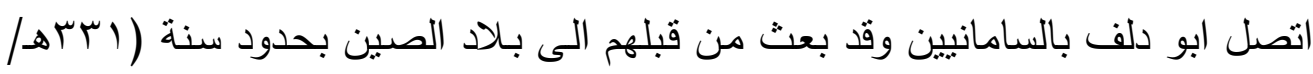

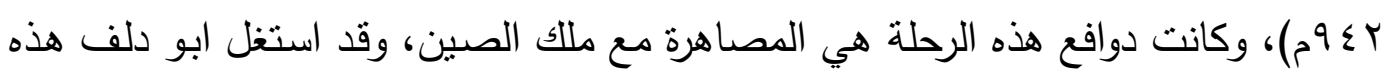

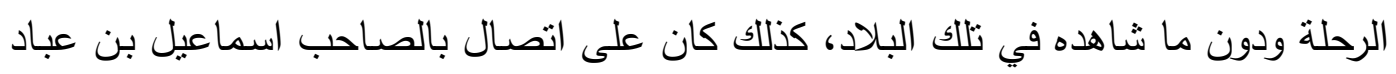

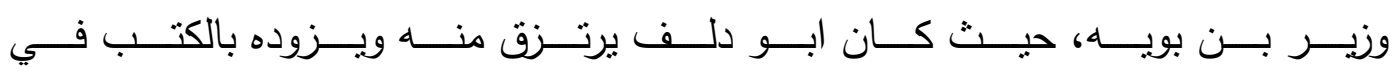

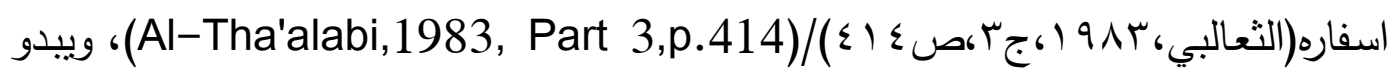

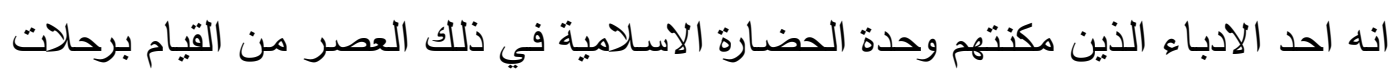

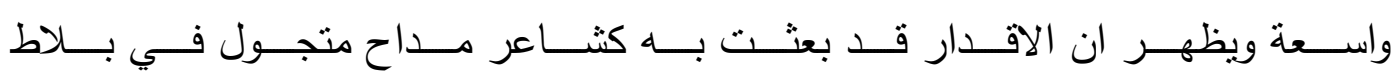

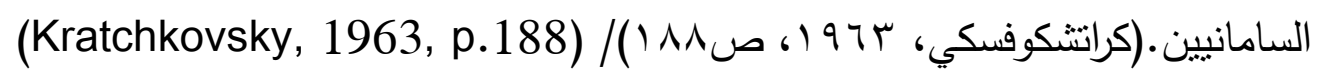
اما طريق رحلته فقد كانت من بخارى في بلاد فارس، ثم اتجه الى تركستان الغربية،

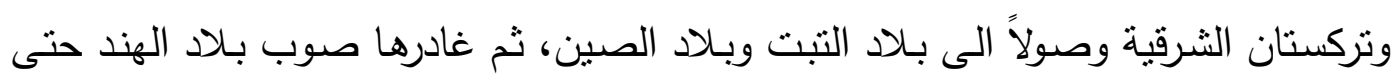

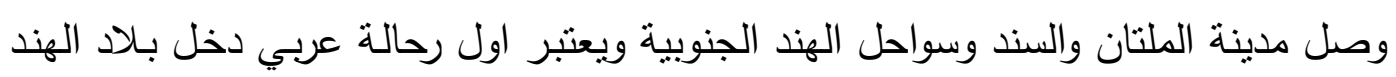

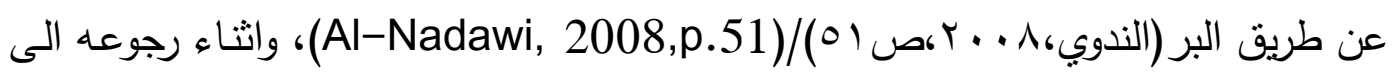

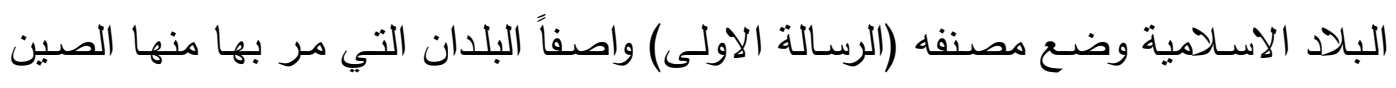

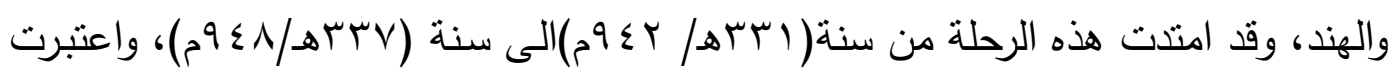

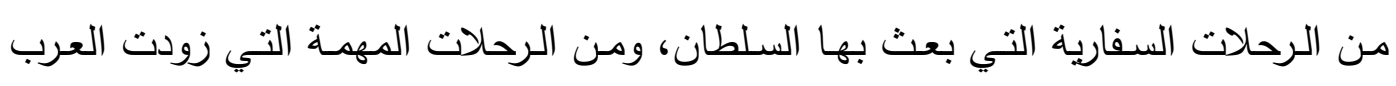

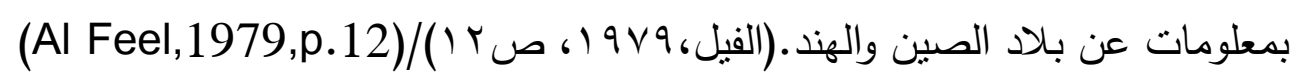

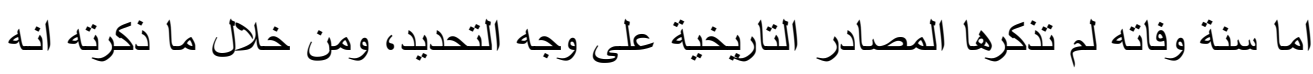

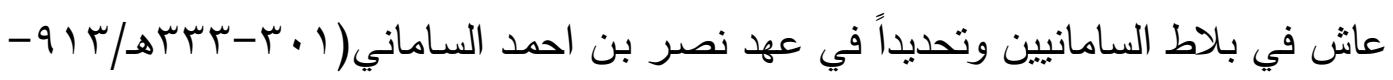

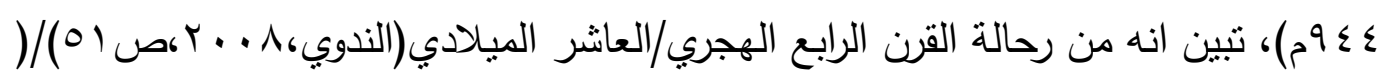
Al-Nadawi, 2008,p.51

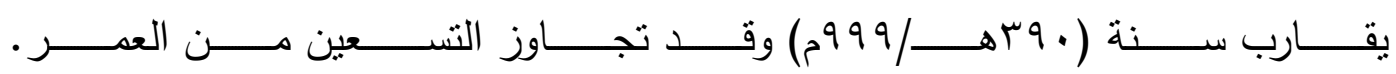

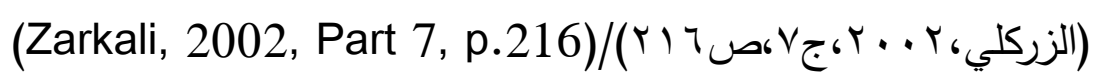


وصف الكتاب ومنهجهُ

ترك لنا ابو دلف وصفاً شيقاً لرحلته في القرن الرابع الهجري/العاشر الميلادي لمناطق

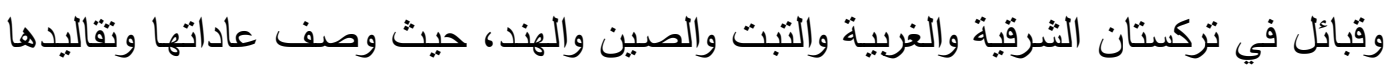
وأعرافها وصناعتها وتجارتها وطرق معيشتها وحياتها العامة ودون ذلك في مصنفه والرسالة الاولى)لا كجغرافي متخصص بل اديب وشاعر يعيش حياة التجول، حاول بقدر استطاعته

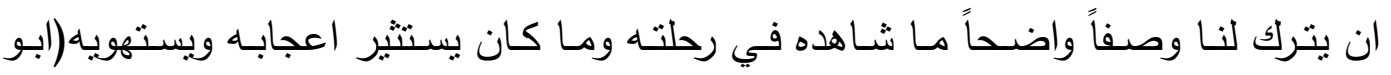

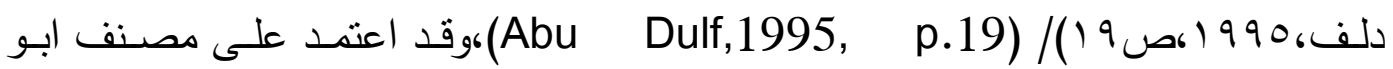
دلف(الرسالة الاولى)عدد من الجغرافيين اللاحقين منهم القزويني صاحب كتاب اثار البلاد

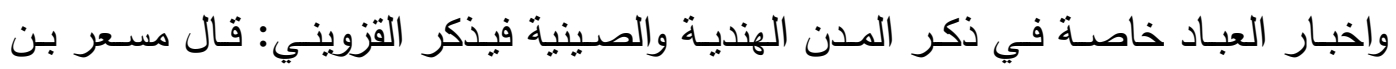

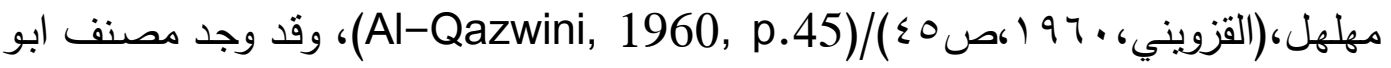

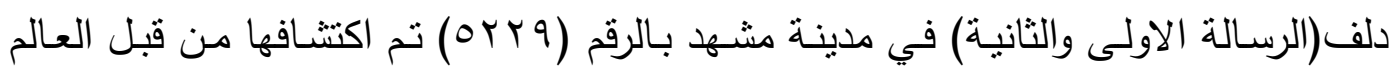

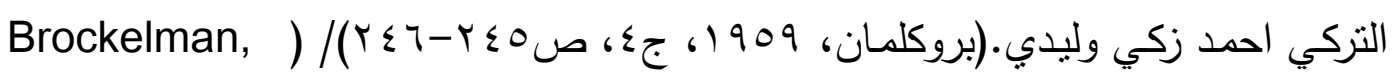
(1959, Part 4, p.245-246

اما منهجه فقد وصف ابو دلف بانه دقيق الملاحظة وذا فطنة في الوصف، وقد تحدث عن عدة جوانب للمجتمعات التي زارهـا ومنهـا الجانب الاقتصـادي فيذكر تجـارة الفلفل والعطور والمسك التي تميزت بها مدن الهندوعند تصويره للحياة الاجتماعية والذي اكثر في

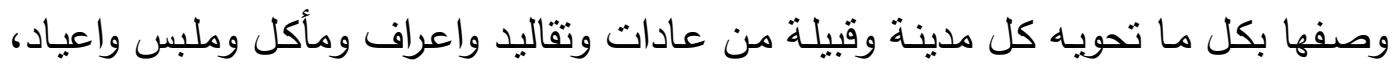

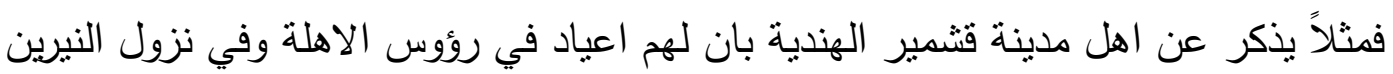

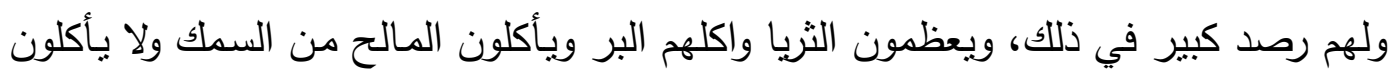
البيض، وفي الجانب السياسي يعطي صورة جديدة عن التوزيع والاتنماء السياسي للقبائل التركية والهندية والصينية، وما تميزت به بعض القبائل من قوة ونفوذ وسيطرة على قبائل

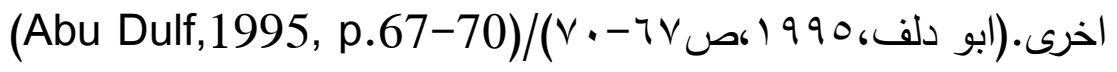

^-برزك بن شهريار/عجائب الهند بره ويحره وجزائره:

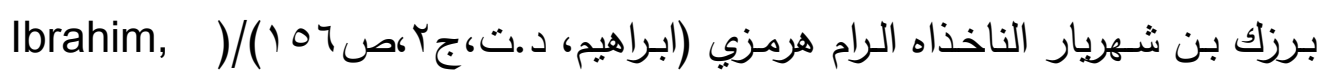

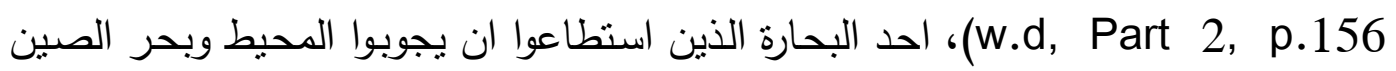

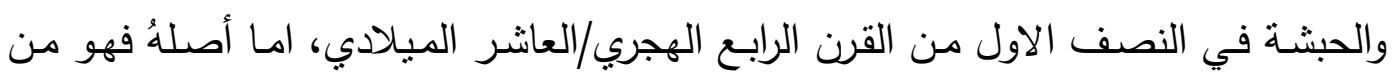

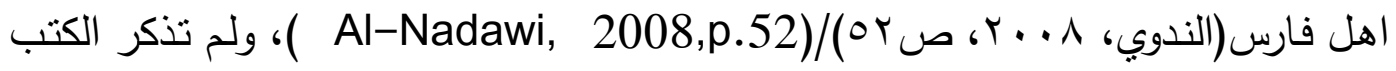

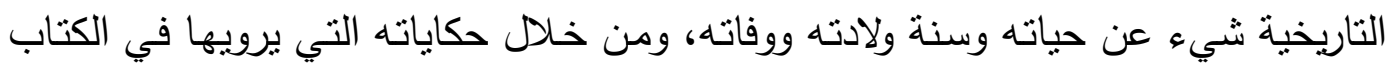

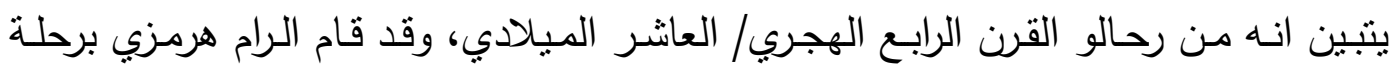


اقتصرت تقريباً على بلاد الهند، فروى ما رأه بعينه وما سمع من التجار والبحريين الذين يثق

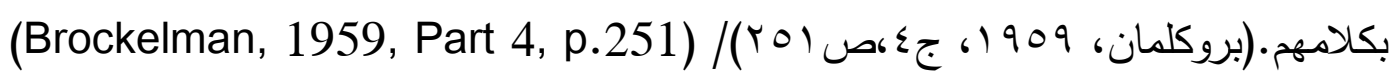
امـا عن مؤلفه(عجائب الهند) ومنهجه، فقد اقتصر اغلب الكتاب على العى ذكر روايات

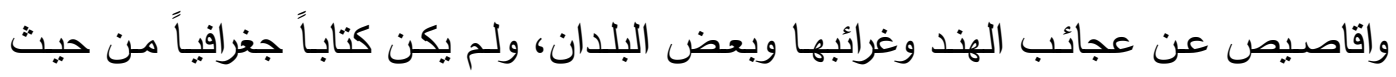

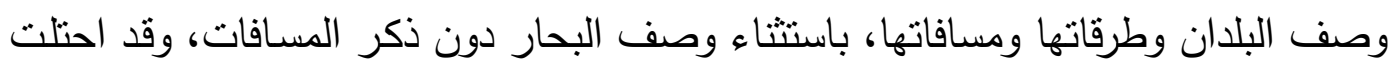

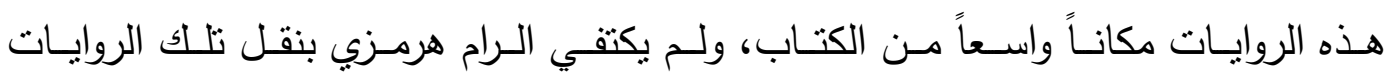

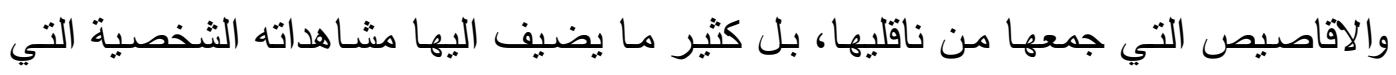

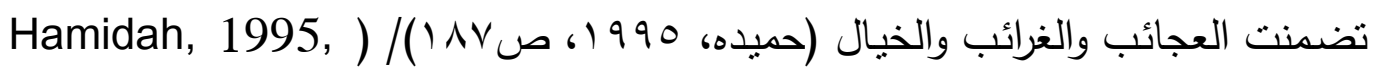

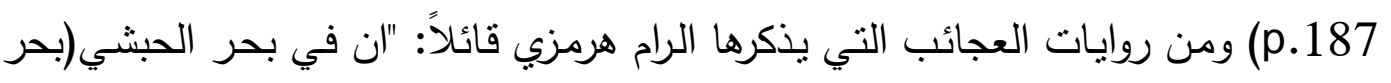

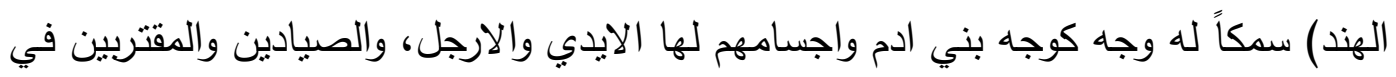

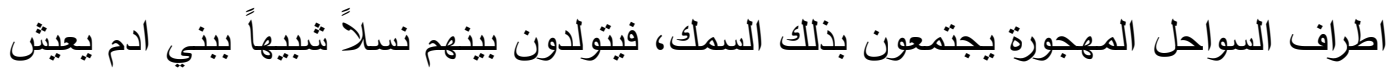

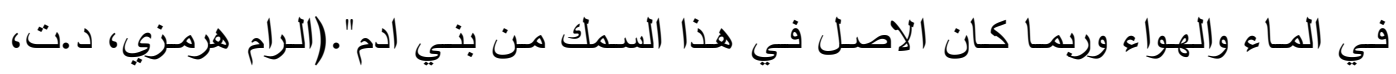

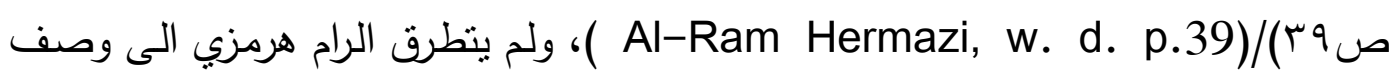

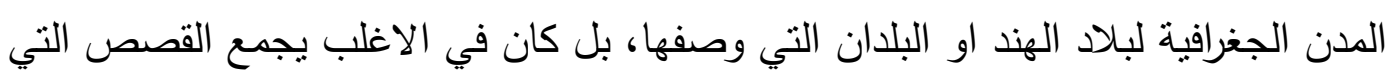

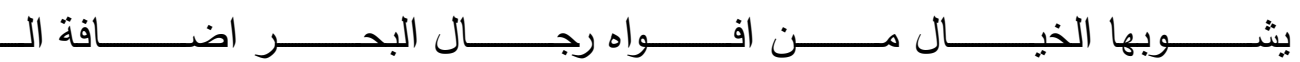

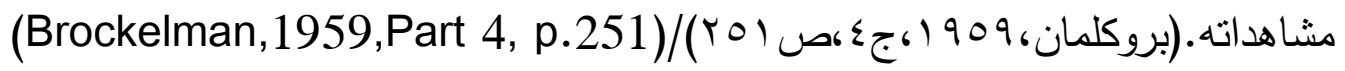

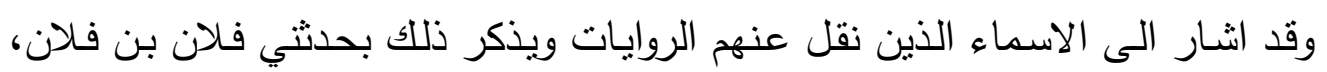

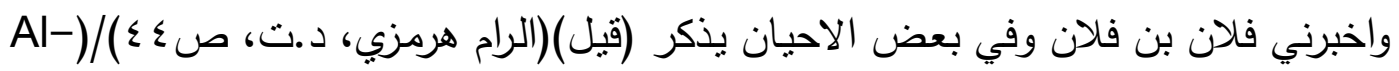
Ram Hermazi, w. d. p.44)، كذلك يذكر الرام هرمزي في كتابه (عجائب الهند) الوقائع والعجائب التي شـاهدها وسمعها في البحار والجزر وشواطئ البلاد وذكر سنوات

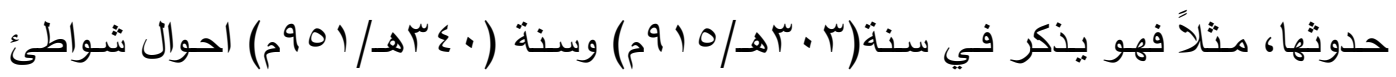
افريقية وسواحل بلاد العرب وجزر الهند والصين، وقيل ان هذا الكتاب قد الفه الرام هرمزي

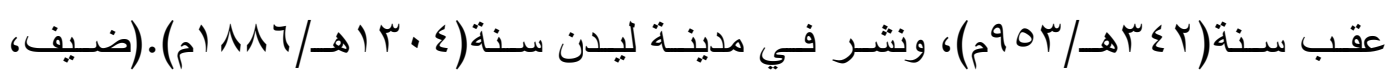
(Dayaf,1987,p.33)/(rr 9 (T) الخاتمة من خلال ما تقدم في تفاصيل موضوع الدراسة يمكن التعرف الى اهم ما توصلت

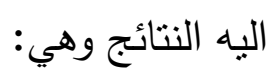
1- معرفة الرحلات الى بلادِ الهند والصين في القرن الرابع الهجري/ العاشر الميلادي.

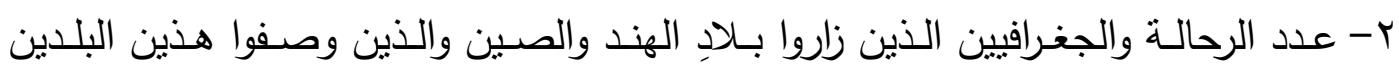

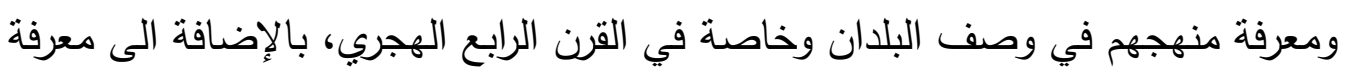
عدد من المراجع الجغرافية التي تطرقت لهذين البلدين. 
ب- الـدور البـارز الذي قدمـه الرحالـة والجغرافيـون في وصـف البلدان وخاصــة بـلادِ الهند والصين واعطاء صورة واضحة ومفصلة حول هذين البلدين سواء في الحياة الاجتماعية او الجغرافيـة، وقد اعتمـدت عليهم اغلب المصـادر التاريخيـة اللاحقة في وصـف تلك

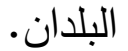

ع - الدوافع التي سبرت من اجلها الرحلات ومنها الرحلـة التجاريـة والرحلـة السفارية ورحلـة طلب العلم ورحلة المشاهدة وحب الاستطلاع. ه-ومن خـلال الدراسـة اتضـح ان بـلادِ الهند والصين من اكثر البلدان التي زارهـا ووصفها الرحالة والجغرافيون العرب والمسلمين وذلك لقربها من حدود البلاد الاسـلامية، وما كانت تحكمها من علاقات تجارية قوية ساعدت الى حد كبير في الترحال او الذهاب الى هذين البلدين، بالإضافة الى حرية الاعتقاد في بلادٍ الهند والصين شجعت بعض علماء الدين المسلمين للرحيل هناك ونشر الدين الاسلامي وبيان مبادئه. واختم بالقول ان الحديث عن الرحلات الى بـلادِ الهند والصين ما زال بحاجة الى مزيد من البحث والاستقصاء خاصـة في مجال المخطوطات التي قد نعثر عليها ونسد بها جانباً مجهولاً.

المصادر باللغة العريبية القرآن الكريم ا. ابراهيم، عبد الله. (د.ت). عـالم القرون الوسطى في اعين المسلمين. منشورات المجمع التقافي. ابو ظبي.

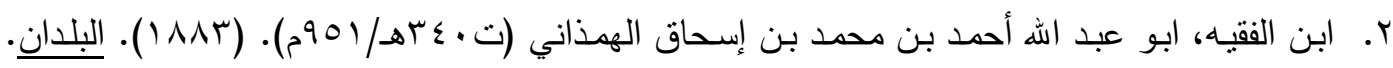
مطبعة بريل. ليدن.

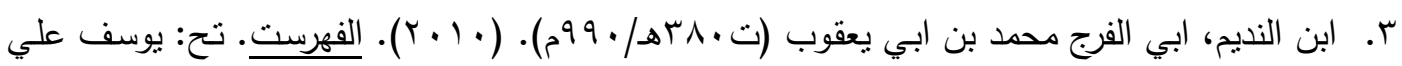
الطويل. ط ז. دار الكتب العلمبة. بيروت.

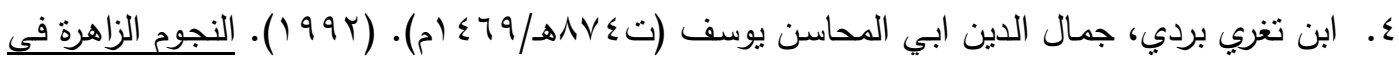
ملوك مصر والقاهرة. تح: محمد حسين شمس الدين. ط الـ لـ دار الكتب العلمية. بيروت.

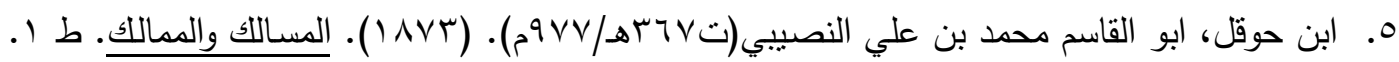
مطبعة بريل. ليدن.

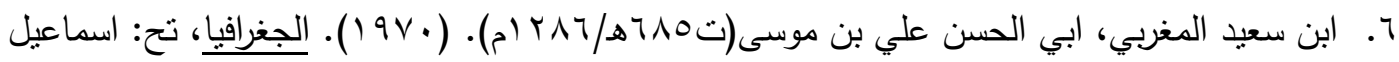

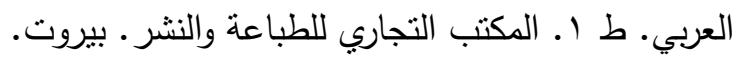
V. ابو دلف، مسعر بن مهلل الخزرجي (ت اواخر القرن الرابح). (990 (1). الرسالة الاولى. تح: مريزن سعيد مريزن. مكتبة الملك فهز الوطنية. مكة. 1. احمد، احمد رمضان. (د.ت). الرحلة والرحالة المسلمون. دار البيان العربي للطباعة والنشر • جدة. 
9 9. الاصطخري، ابو اسحاق ابراهيم بن محمد الفارسي (ت ؟ كهـ/ 90Vم). (9rV I ). مساللك الممالك. مطبعة بريل. ليدن.

• (. بروكلمان، كارل. (909 (1). تاريخ الادب العربي. ترجمة: يعقوب بكر ورمضان عبد التواب. ط بـ دار

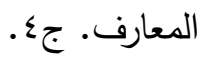

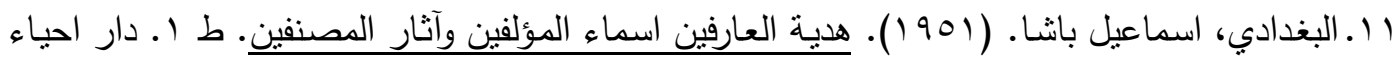

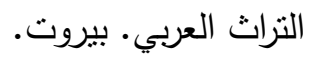

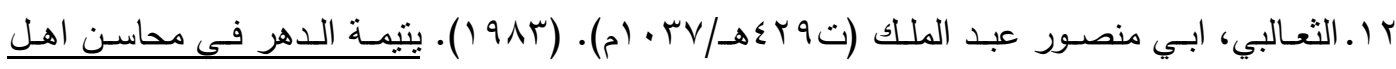

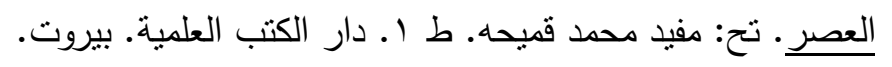

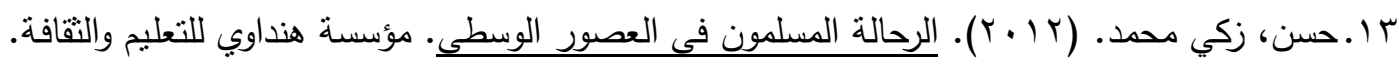
القاهرة.

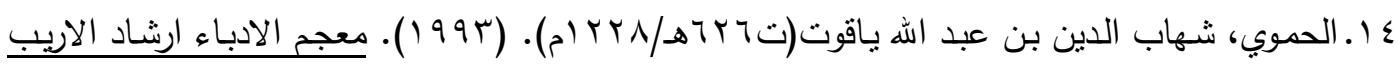

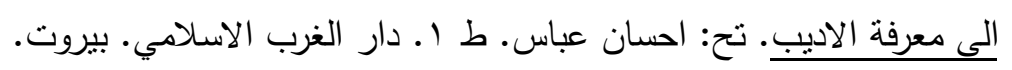

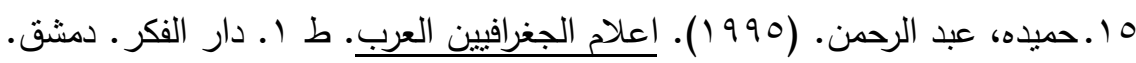

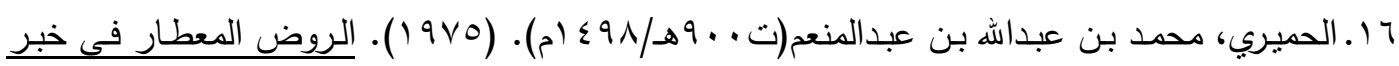

الاقطار • تح: احسان عباس. ط ا. ـ مكتبة لبنان. بيروت.

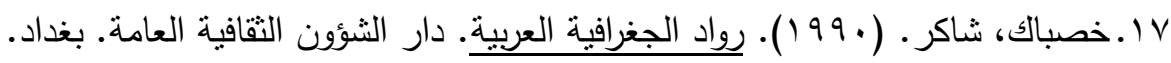

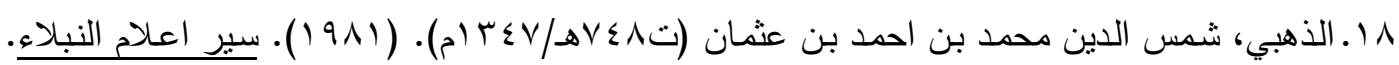

تح: مأمون الطاغرجي. ط الـ ـ مؤسسة الرسالة. بيروت.

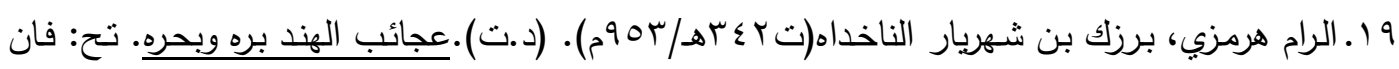

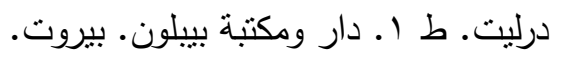

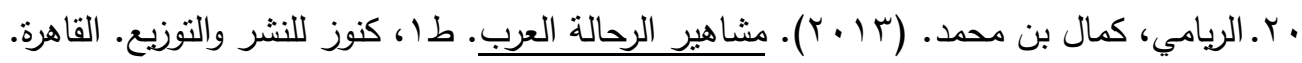

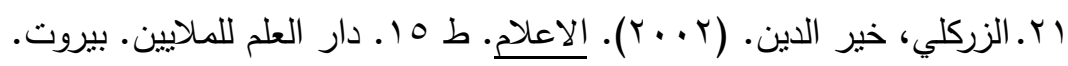

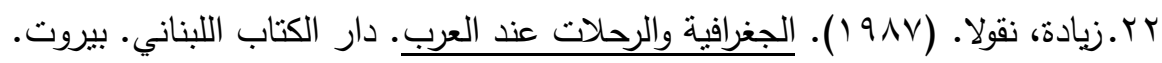

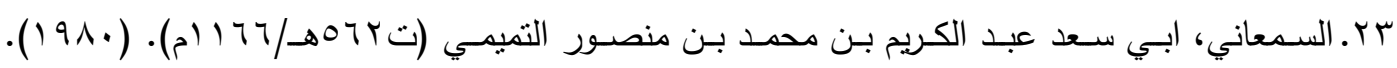
الانساب. تح: عبد الرحمن بن يحيى. ط ب ـ مكتبة ابن تميمة. القاهرة.

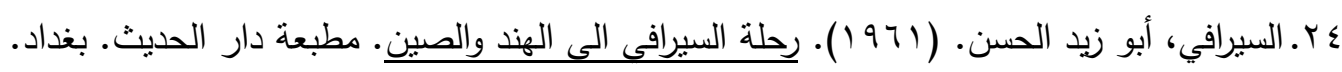

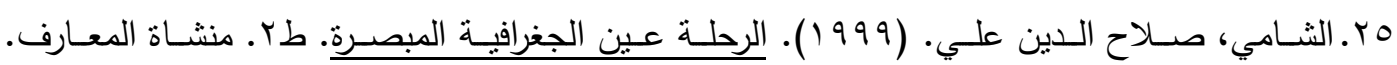
الاسكندرية.

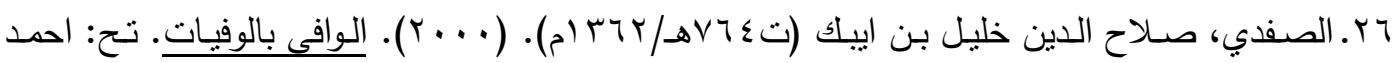
الارناؤوط. ط ا ـ دار احياء التراث العربي. بيروت. r Y rV

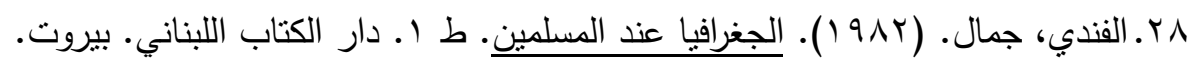

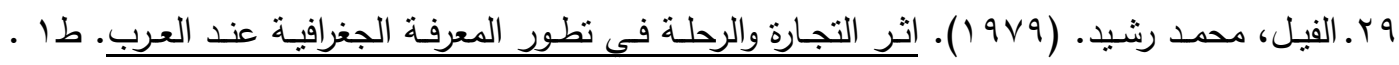
الجمعية الجغرافية الكويتية. الكويت. 


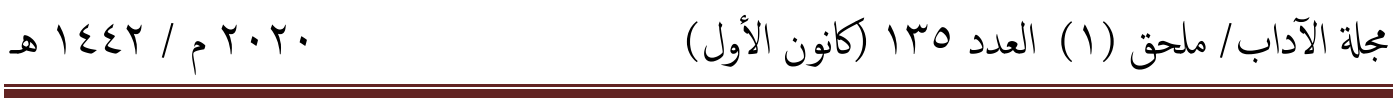

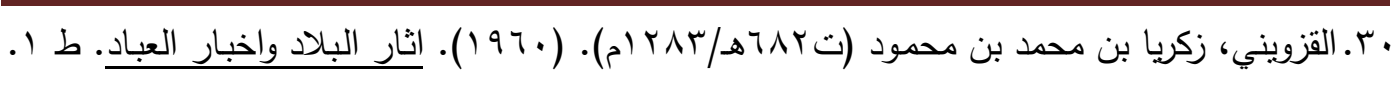

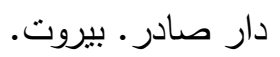

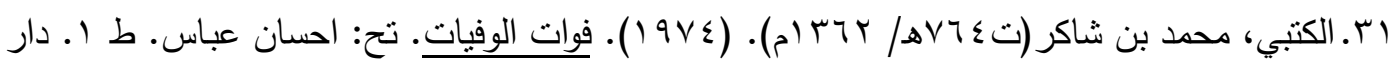

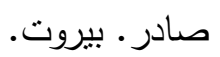

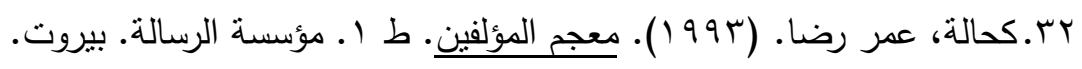

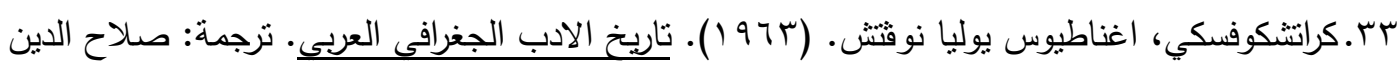

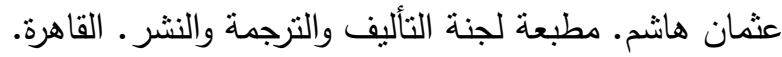

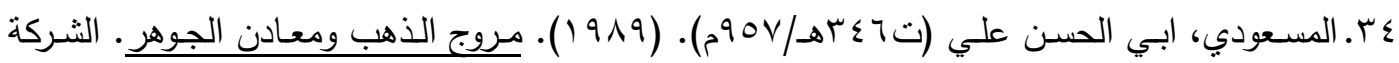

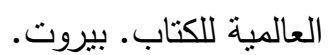

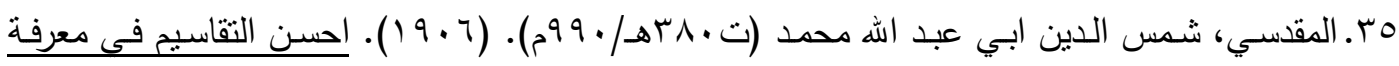

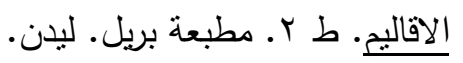

4T.مينورسكي، م. ف. (1910). الجغرافيون والرحالـة المسلمون. ترجمة: عبد الرحمن حميده. الجمعية

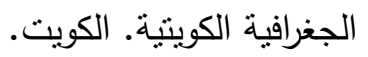

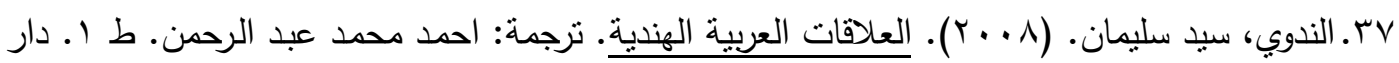
الكتب والوثائق القومية. القاهرة. - الكان.

المصادر باللغة الانكليزية

\section{Holy Quran}

1. Ibrahim, Abdullah.(w. d.). Medieval world in the eyes of Muslims. Publications of the Cultural Foundation. Abu Dhabi.

2. Ibn al-Faqih, Abu Abdullah Ahmad bin Muhammad bin Ishaq al-Hamdhani (died . 340 AH / 951). (1883). Al Buldan . Braille Press. Leiden.

3. Ibn al-Nadim, Abu al-Faraj Muhammad bin Abi Ya`qub (died 380 AH / 990 CE). (2010). Al Fahrast. achieved : Youssef Ali Al-Tawil. $3^{\text {rd }}$ edition . House of Scientific Books. Beirut.

4. Ibn Tigray Bardi, Jamal al-Din Abi Al-Mahasin Yusef (died.874 AH/1469). (1992).Al Nujum Al Zahira Fi Muluk Miser Walkahira, achieved : Muhammad Hussein Shams al-Din. $1^{\text {st }}$ edition . House of Scientific Books. Beirut.

5. Ibn Hawqal, Abu al-Qasim Muhammad bin Ali al-Nasibi (died . 367 AH / 977). (1873). Al Masalik Wal Mamalik, $1^{\text {st }}$ edition. Braille Press. Leiden.

6. Ibn Saeed Al-Maghrabi, Abi Al-Hassan Ali Ibn Musa (died. 685 AH / 1286). (1970). Geography, achieved : Ismail Al-Arabi. $1^{\text {st }}$ edition, The Commercial Office for Printing and Publishing. Beirut.

7. Abu Dulf, Mas`ar bin Muhallal al-Khazraji (died. Late 4th century). (1995). The first message. Achieved : Merizen Saeed Merizen. King Fahd National Library. Mecca.

8. Ahmed, Ahmed Ramadan. (w. d) Travel and Muslim travelers. Dar Al Bayan Al Arabi for Printing and Publishing. Jeddah.

9. Al-Ashtari, Abu Ishaq Ibrahim bin Muhammad al-Farsi (Died . 346 AH / 957). (1927). Masalik Al Mamalik. Braille Press. Leiden.

10. Brockelman, Carl. (1959). History of Arabic literature. Translation: Yaqoub Bakr and Ramadan Abdel Tawab. $3^{\text {rd }}$. House of Knowledge. 
11. Al-Baghdadi, Ismail Pasha. (1951). The gift of those who know the names of the authors and classifiers works, $1^{\text {st }}$ edition. House of Arab Heritage Revival. Beirut.

12. Al-Tha'alabi, Abu Mansour Abd al-Malik (died . 429 AH / 1037). (1983). The orphan of the age in the goodness of the people of the age. Achieved : Moufid Muhammad Qumaiha. $1^{\text {st }}$ edition . House of Scientific Books. Beirut.

13. Hassan, Zaki Muhammad. (2012). Muslim travelers in the Middle Ages. Hindawi Foundation for Education and Culture. Cairo.

14. Al-Hamwi, Shihab al-Din bin Abdullah Yaqout (d. 626 AH / 1228). (1993). Dictionary of writers guide Al-Areeb to know the writer. Achieved : Ihssan Abbas. $1^{\text {st }}$ edition. West Islam House of the West. Beirut

15. Hamidah, Abdel Rahman. (1995). Scientists of Arab geographers. $1^{\text {st }}$ edition. House of thought. Damascus.

16. Al-Hamiri, Muhammad bin Abdullah bin Abdel-Moneim (died . $900 \mathrm{AH} /$ 1498). (1975). Rawd Almttar Fi Khbar Al Aqtar. Achieved: Ihssan Abbas. $1^{\text {st }}$ edition , The Library of Lebanon. Beirut.

17. Khasabak, Shaker. (1990). Pioneers of Arabic geography. General Cultural Affairs House. Baghdad.

18. Al-Dhahabi, Shams al-Din Muhammad bin Ahmed bin Othman (died . 748 AH / 1347). (1981). The functioning of the nobles' flags. Achieved : Mamoun Al-Taghraji. $1^{\text {st }}$ edition . Al-Resala Corporation. Beirut.

19. Al-Ram Hermazi, Barzak bin Shahryar Al-Nakhdhah (died . 342 AH / 953). (without date.) The wonders of India, onshore and offshore. Achieved : Van Durlett. $1^{\text {st }}$ edition. Byblon House and Library. Beirut.

20. Riyami, Kamal bin Mohammed. (2013). Famous Arab travelers. 1st edition, treasures for publication and distribution. Cairo.

21. Zarkali, Khair al-Din. (2002). Al Alaam $\cdot 1^{\text {st }}$ edition . House of Knowledge for millions. Beirut.

22. Ziyada, Nicola. (1987). Geography and travels with Arabs. Lebanese Book House. Beirut.

23. Al Samani, Abu Saad Abdul Karim bin Muhammad bin Mansour Al Tamimi (d. 562 AH / 1166). (1980). Genealogy. Achieved : Abdul Rahman bin Yahya. $2^{\text {nd }}$. Ibn Tamima Library. Cairo.

24. Al-Serafi, Abu Zaid Al-Hassan. (1961). Serafi trip to India and China. Dar Al-Hadith Press. Baghdad.

25. Al-Shami, Salah Al-Din Ali. (1999). The travel was named Geographical Vision. $2^{\text {nd }}$ edition. Knowledge establishment . Alexandria.

26. Al-Safadi, Salah al-Din Khalil bin Ibik (died . 764 AH / 1362 AD). (2000). Al Wafi Bilwafyyat . achieved : Ahmed Arnaout. 1st edition. House of Arab Heritage Revival. Beirut.

27. Dayaf, Shawky. (1987). Trips. $4^{\text {th }}$ edition . Dar Al-Maaref. Cairo.

28. Fendi, Jamal. (1982). Geography of Muslims. $1^{\text {st }}$ edition The Lebanese Book House. Beirut.

29. Al Feel, Mohammed Rashid. (1979). The effect of trade and travel on the development of geographical knowledge among Arabs. $1^{\text {st }}$ edition . Kuwait Geographic Society. Kuwait.

30. Al-Qazwini, Zakaria bin Muhammad bin Mahmoud (died. 682 AH / 1283). (1960). The ruins of the country and the news of the servants. $1^{\text {st }}$ edition . Dar Sader. Beirut.

31. Al-Ketbi, Muhammad bin Shaker (died . 764 AH / 1362 AD). (1974). Fawat

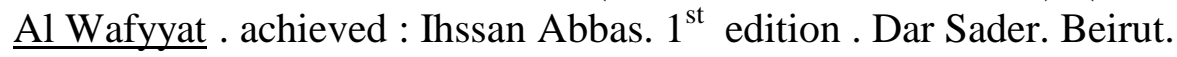




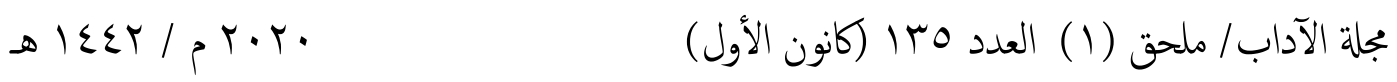

32. Kahhala , Omar Reda. (1993). A Dictionary of Authors. 1stedition . AlResala Corporation. Beirut.

33. Kratchkovsky, Ignatius Yulia Novich. (1963). History of Arab geographical literature. Translation: Salah Al-Din Othman Hashem. Copyright, Translation and Publishing Committee Press. Cairo.

34. Al-Masoudi, Abu Al-Hassan Ali (died . 346 AH / 957). (1989). Meadows Gold and Essence Minerals. International Book Company. Beirut.

35. Al-Maqdisi, Shams al-Din Abi Abdullah Muhammad (died 380 AH / 990). (1906). The best divisions in knowledge of the regions. $2^{\text {nd }}$ edition . Braille Press. Leiden.

36. Menorsky, M. F. (1985). Muslim geographers and travelers. Translation: Abdul Rahman Hamida. Kuwait Geographic Society. Kuwait.

37. Al-Nadawi, Syed Sulaiman. (2008). Arab Indian Relations. Translation: Ahmed Mohamed Abdel-Rahman. $1^{\text {st }}$ edition, House of books and national documents. Cairo. 


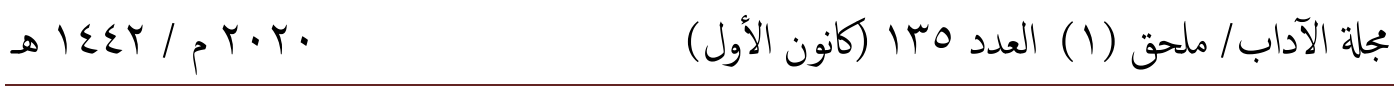

Geographical trips to countries of India and China in the fourth century AH / 10th century AD Derived Search

\author{
Ahmed Nashmi Jiyad Al-Alaywi \\ nashmi20202@gmail.com \\ Assist Prof. Dr. Ikrima Kamel Al-Saadi \\ University of Al Mustansiriya \\ College of Education / Department of History
}

\begin{abstract}
The books of geographical trips are considered one of the most important works in Islamic history, but they are the mainstay of those works, because of the abundant scientific material they contain in describing countries, their cities, customs and traditions. Most primary sources and secondary references have relied on them for mentioning and describing countries, With regard to the topic of research, which is geographical trips to the countries of India and China in the fourth century $\mathrm{AH}$, a number of travelers emerged in that century, including those who traveled to the countries of India and China, and some of them described these two countries. Detailed in terms of their translations, methodology, and trips to the countries of India and China. The topic is of great importance. It highlights the most important trips to the countries of India and China in that century. Keywords: (Geographic excursions, excursions, and geographers)
\end{abstract}

